OPEN ACCESS

Edited by:

Emily Keshner,

Temple University, United States

Reviewed by:

Lorenz Assländer,

Universität Konstanz, Germany

Robert Peterka,

Oregon Health \& Science University,

United States

Pierre-Paul Vidal,

Université Paris Descartes, France

*Correspondence:

Patrick A. Forbes

p.forbes@erasmusmc.nl

Specialty section:

This article was submitted to

Movement Disorders,

a section of the journal

Frontiers in Neurology

Received: 29 June 2018 Accepted: 03 October 2018

Published: 26 October 2018

Citation:

Rasman BG, Forbes PA, Tisserand $R$ and Blouin J-S (2018) Sensorimotor Manipulations of the Balance Control

Loop-Beyond Imposed External Perturbations. Front. Neurol. 9:899,

doi: 10.3389/fneur.2018.00899

\section{Sensorimotor Manipulations of the Balance Control Loop-Beyond Imposed External Perturbations}

\author{
Brandon G. Rasman ${ }^{1,2}$, Patrick A. Forbes ${ }^{1,3 *}$, Romain Tisserand ${ }^{2}$ and \\ Jean-Sébastien Blouin ${ }^{2,4,5}$
}

${ }^{1}$ Department of Neuroscience, Erasmus Medical Center, Rotterdam, Netherlands, ${ }^{2}$ School of Kinesiology, University of British Columbia, Vancouver, BC, Canada, ${ }^{3}$ Department of Biomechanical Engineering, Faculty of Mechanical, Maritime and Materials Engineering, Delft University of Technology, Delft, Netherlands, ${ }^{4}$ Djavad Mowafaghian Center for Brain Health, University of British Columbia, Vancouver, BC, Canada, ${ }^{5}$ Institute for Computing, Information and Cognitive Systems, University of British Columbia, Vancouver, BC, Canada

Standing balance relies on the integration of multiple sensory inputs to generate the motor commands required to stand. Mechanical and sensory perturbations elicit compensatory postural responses that are interpreted as a window into the sensorimotor processing involved in balance control. Popular methods involve imposed external perturbations that disrupt the control of quiet stance. Although these approaches provide critical information on how the balance system responds to external disturbances, the control mechanisms involved in correcting for these errors may differ from those responsible for the regulation of quiet standing. Alternative approaches use manipulations of the balance control loop to alter the relationship between sensory and motor cues. Coupled with imposed perturbations, these manipulations of the balance control loop provide unique opportunities to reveal how sensory and motor signals are integrated to control the upright body. In this review, we first explore imposed perturbation approaches that have been used to investigate the neural control of standing balance. We emphasize imposed perturbations that only elicit balance responses when the disturbing stimuli are relevant to the balance task. Next, we highlight manipulations of the balance control loop that, when carefully implemented, replicate and/or alter the sensorimotor dynamics of quiet standing. We further describe how manipulations of the balance control loop can be used in combination with imposed perturbations to characterize mechanistic principles underlying the control of standing balance. We propose that recent developments in the use of robotics and sensory manipulations will continue to enable new possibilities for simulating and/or altering the sensorimotor control of standing beyond compensatory responses to imposed external perturbations.

Keywords: imposed perturbations, ongoing human in the loop manipulations, balance control, quiet standing, robotics, sensory stimulation 


\section{INTRODUCTION}

Our ability to stand upright requires accurate estimation about the orientation of the body with respect to gravity as well as the relative relationships between body segments. These estimates are formed through multisensory integration of information arising from visual, vestibular, somatosensory and auditory sensory systems. Imposed perturbations of the sensory/motor systems and manipulations of the balance control loop provide methods of disrupting and/or modifying the balance controller. These approaches, however, differ. Imposed perturbations (transient or continuous) evoke external error signal inputs while manipulations of the balance control loop are designed to modify the sensorimotor relationships required to control quiet stance. Both approaches have proven critical in unraveling fundamental sensorimotor principles underlying standing balance. In this review, we explore perturbation and manipulation approaches used to probe the balance system. We first provide an overview of the sensorimotor and mechanical characteristics that are relevant for the control of standing balance. Then, we discuss imposed external perturbations that have enabled researchers to investigate how the balance system responds to these unexpected disturbances. Here, we operationally define imposed perturbations as methods which disrupt quiet standing behavior and represent external error signals for the balance system. As such, the parameters of the imposed external perturbations are designed exclusively by the experimenter. We subsequently present manipulations of the balance control loop that can be implemented to alter sensory feedback and/or their relationships with motor outputs during the ongoing control of quiet standing balance. Importantly, although these techniques can involve physical and/or sensory alterations, we define them as manipulations (rather than perturbations) as they are designed to modify relationships within the balance control loop such that their effects are a function of the action of the subject (i.e. human in the loop manipulations). Finally, we emphasize how manipulations of the balance control loop altering ongoing feedback can be combined with imposed perturbations to reveal sensorimotor principles of standing balance. Throughout this review, we prioritize information gained from experimental approaches applied to healthy human volunteers. Where appropriate, we relate these findings to observations gathered from clinical populations (e.g., persons with vestibular loss), whose behavior may complement our insight into the control of standing balance.

\section{SENSORIMOTOR AND MECHANICAL ASPECTS OF STANDING BALANCE}

The upright bipedal posture adopted for standing balance is mechanically unstable. When the vertical projection of the whole-body deviates from the ankle joint center of rotation, gravity acting on the body increases the magnitude of the toppling torque and must be compensated by active and passive forces. Consequently, although standing may be referred to as quiet stance or static balance, the acceleration of the whole-body center of mass is constantly varying in three-dimensional space.
The mechanics of standing balance involve both large and fine adjustments used to stabilize the whole-body and the relative orientation of body segments (1-4). The mechanics of standing balance are often simplified by assuming that movement only occurs around a limited number of joints. In the anteroposterior direction, the standing body is commonly represented using a single-link inverted pendulum model where whole-body movements occur mainly around the ankle joints (5-8). In the mediolateral direction, an inverted pendulum with dual links (i.e., both limbs) has been proposed (9-11), with whole-body motion occurring around both the ankle and hip joints. The differential equation of an inverted pendulum is therefore used to describe the relationship between the net torque and wholebody angle when a person stands; explaining how body inertia mechanically filters muscle activation during standing, resulting in low frequency movements of the whole-body (typically below $0.5 \mathrm{~Hz}$ for quiet standing sway) $(8,12-14)$.

Given that forces are developed when musculoskeletal tissues are deformed, it has been proposed that tonic muscle activity may be sufficient to maintain standing balance passively (11, 15). For balancing along the anteroposterior direction, however, the toppling gravito-inertial torque associated with whole-body movements exceeds the intrinsic stabilizing torque developed by the viscoelastic forces during deformation of ankle tissues $(16,17)$. Consequently, active neural control of the ankle and hip muscles (as well as those acting at other joints) is required to stabilize the body and modulate the net forces and torques delivered through the feet onto the support surface (18-23). The active maintenance of standing balance involves a sensorimotor control loop that detects body orientation/motion and generates the stabilizing forces and torques required to remain upright (Figure 1). Information regarding the orientation of the body with respect to gravity and the relative relationship between body segments is provided by integrating multiple cues from sensors located throughout the body. In the following paragraphs, we describe briefly the balance-relevant sensory code provided by these sensors as they relate to the frequency characteristics of standing balance.

\section{Balance-Relevant Sensory Code}

Sensory inputs from the visual, vestibular, somatosensory and auditory systems all contribute to the control of standing balance. The information provided by individual sensory cues is shaped by the dynamics of each sensor and the coordinate system in which they are referenced [for a review of sensory dynamics related to standing balance, see (24)]. To be relevant for standing balance, a sensor must be capable of encoding frequencies up to and beyond those comprising the dynamics of the standing body; i.e., the dynamics of a sensor must be greater than the actuator, which must be greater than the mechanical system being controlled (25-27). Therefore, sensors that primarily encode low frequency (and static) information may be more likely to contribute to the low frequency control of quiet standing balance whereas those encoding higher frequencies may be more helpful in responding to imposed external perturbations.

The somatosensory system refers to a group of receptors found throughout the muscles, joints, and skin of the body. Several of these mechanoreceptors relay position and motion 


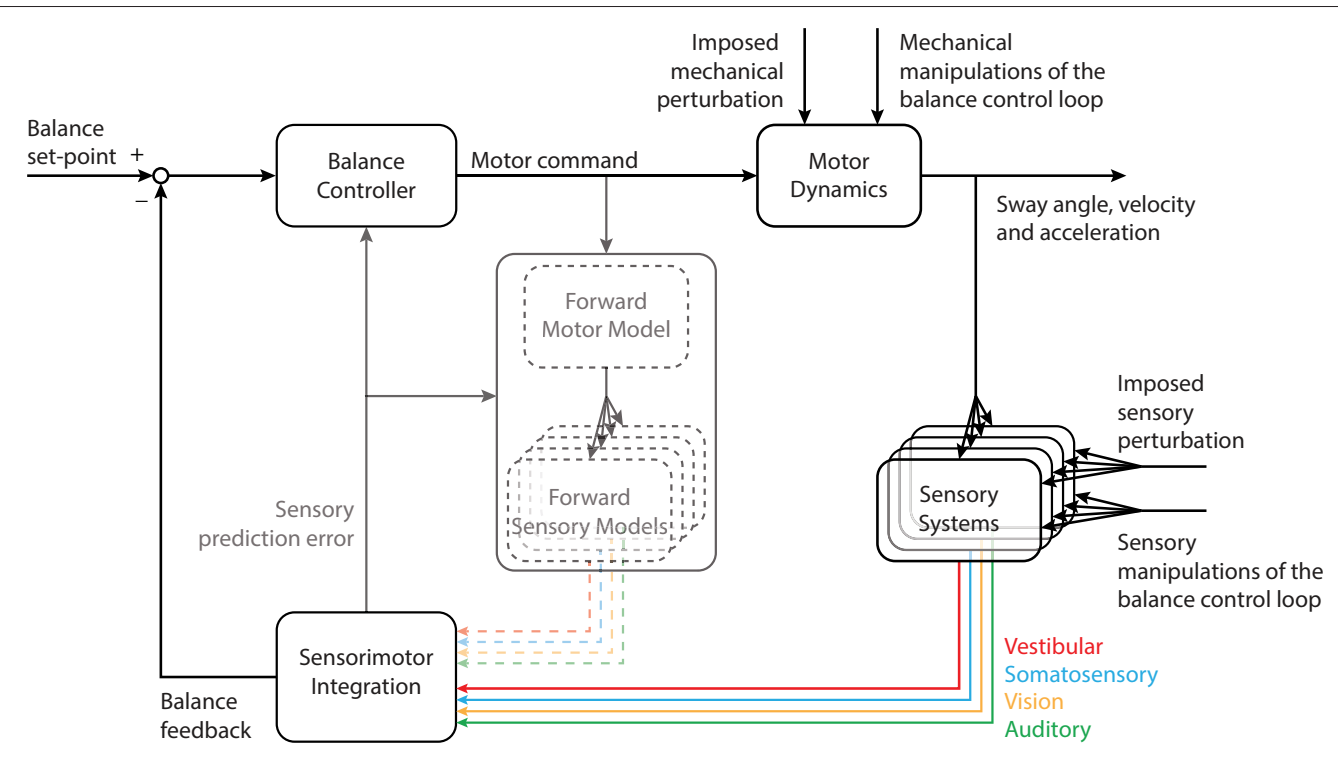

FIGURE 1 | Schematic of the balance control loop depicting the relationship between motor command, sensory feedback and multisensory integration. Sensory cues convey information about the external world and the body's orientation within it. This information is integrated with motor commands to estimate sensory prediction errors. Because these aspects of the balance control loop are not the focus of this review, they have been grayed out in the figure [see (24) for a more detailed exploration of these principles]. Mechanical and sensory inputs to the control loop illustrate a conceptual representation of imposed perturbations or manipulations of the balance control loop applied to understand the control of standing balance. Details on the implementation of imposed perturbations or manipulations of the balance control loop are presented in Figure 2. Portions of this figure were adapted from Forbes et al. (24).

cues referenced to the body and its different segments, also known as proprioception [(28-33); for a comprehensive review, see (34)]. Collectively, muscle and joint receptors encode static and dynamic joint angle and/or muscle force. Although cutaneous receptors may also encode joint angle (35), those located in the glabrous skin of the foot sole act as an interface between the external world and the body. They can sense contact forces and texture of the support surface that may be used for standing balance $(36,37)$. The visual system encodes cues referenced to the external world derived from our field of view. From visual inflow, motion signals of the surrounding world (object-motion) and of the body within the world (selfmotion) are extracted and provide cues to stabilize the upright body (38). The accessory optic system (a series of nuclei in the midbrain with efferent connections to the brainstem and cerebellum) likely plays an important role for balance control given its preference for low frequency stimuli and interaction with vestibular inputs $(39,40)$. Visual signals further provide cues on the spatial orientation of objects in our surroundings that may be used for controlling posture and responding to disturbances $(41,42)$. The vestibular end organs, which are fixed within the inner ears, sense three dimensional orientation and inertial cues of the head-in-space (43). Two subtypes of end organs, the otoliths and the semicircular canals, allow the vestibular apparatus to encode translational and angular motion, respectively (44). Because otoliths also encode head orientation relative to gravity, the distinction between head orientation with respect to gravity and head acceleration signals can be achieved by the integration of otolith and canal cues along with visual and somatogravic ones (45-49). Hence, information derived from the peripheral vestibular apparatus provides important cues needed for the control of standing balance. The auditory system, often overlooked for its role in balance control, is situated alongside the vestibular apparatus in the inner ear. Auditory cues can be used for spatial localization of the head-in-space and produce illusions of self-motion $(50,51)$, most prominently in the absence of vision (52). When standing, stationary sound cues that are coherent with other sensory signals of balance allow subjects to construct spatial auditory maps that improve postural stability [see review by Campos et al. (53)].

Various imposed stimuli or sensory manipulations of the balance control loop can be used to investigate the role of sensory cues in balance control. In the following sections, we first describe imposed external perturbations that have been used to study the reactive control of standing balance. We emphasize that stimuli of this type evoke compensatory postural responses to external disturbances. Therefore, a particular focus is put on stimuli that specifically target balance control as opposed to methods that evoke responses irrespective of the need to balance upright (e.g., stretch reflexes). We subsequently present and propose methods that alter the ongoing control of quiet standing balance in order to assess the organization and potential adaptability of the neural control of standing balance.

\section{IMPOSED EXTERNAL PERTURBATIONS TO CHARACTERIZE STANDING BALANCE}

Imposed perturbations have been applied extensively to assess the control of standing balance. These perturbations are 
often designed by experimenters to be similar to disturbances experienced during daily activities (e.g., standing on a bus that suddenly accelerates) and can have a range of amplitudes, velocities and/or accelerations. Carefully applied perturbations have been used to reveal important aspects of standing balance. For example, using imposed external perturbations researchers have estimated the passive and active mechanisms underlying standing balance and revealed how error signals are integrated and transformed to maintain upright stance (see subsections below). A point to consider, however, is that imposed perturbations represent an external error signal that is independent from the quiet standing balancing task (see Figure 2A). Quiet standing balance behaviors can be described using numerical models that also characterize responses to imposed perturbations $(54,55)$, but it cannot be assumed that the neural processes involved in these two scenarios are identical. Consequently, perturbations imposed on standing participants inform a researcher on how individuals respond to an external disturbance as opposed to how they integrate and combine multisensory cues to maintain quiet stance. Specifically, imposed perturbations may evoke responses originating from sensory cues activated by the perturbation that may not contribute to the control of quiet upright stance. Furthermore, it is currently not possible to estimate the contributions of ongoing sensory feedback involved in maintaining quiet standing balance by introducing additional sensory inputs through imposed perturbations [see (56) for locomotor analogy]. Nevertheless, there are certain imposed perturbations that only evoke wholebody responses when participants are engaged in standing balance and these may reveal fundamental principles underlying its control. We will discuss these different approaches in the following paragraphs but the reader is invited to consult (57-59) for comprehensive reviews of imposed perturbation approaches.

\section{Mechanical Perturbations}

A wide variety of mechanical perturbations have been used to study compensatory responses during standing balance. Popular approaches include rotating (60-63) or translating (64-67) the support surface of standing subjects, while others use forces or torques applied to specific points on the body (68-70). When applied as discrete physical perturbations to standing participants, mechanical perturbations evoke stereotypical transient muscle and whole-body responses (71-76). To align better with the continuous control of standing balance and to characterize muscle and whole-body responses to ongoing disturbances, other researchers have used prolonged mechanical oscillations to study standing balance (20,77-79). Using specific perturbation frequencies and magnitudes, the relationship between oscillatory perturbations and muscle/postural responses can be estimated (80-82). Coupled with sensorimotor modeling, the input/output estimates from prolonged perturbations can reveal fundamental properties of upright stance such as stiffness, damping and time delays of the balance control loop. In animal models, mechanical support surface perturbation approaches have also led to the characterization of synergistic muscle responses in balance control (83-86). Coordinated patterns of muscle activity (i.e. "synergies" or "motor modules") are thought to be flexibly combined by the nervous system to facilitate functional motor control, and account for spatial, temporal and postural strategy variability in human responses to multidirectional imposed perturbations $(87,88)$. Mechanical perturbations can also be applied to perturb somatosensory cues of motion without physically moving the whole-body or its support surface. For instance, in "light touch" experiments, perturbations are provided through motion of an external reference that a subject is in contact with (often with a finger) that does not provide mechanical support (89-91). Recently, Asslander et al. (92) perturbed the touch surface that subjects contacted with a finger at different positions with respect to their body. The authors proposed that the brain transforms sensory information derived from light touch into a reference frame for standing balance by estimating the distance between the whole-body center of mass and the finger.

Mechanical stimuli can also be applied to activate cutaneous or muscle receptors. For example, vibration stimuli can be delivered at the foot soles or muscle tendons and adjusted (amplitude and frequency) to elicit responses in cutaneous (primarily fast-adapting) and muscle spindle (primarily Ia) afferents (93-95). When applied to standing participants, these stimuli evoke well-defined and direction-specific whole-body and muscle responses (96-99). Simultaneous vibration of cutaneous and muscle receptors elicits body tilts equal to the vector summation of individual responses (100), suggesting a linear combination of these specific stimuli. However, vibration and stretch stimuli are unspecific to balance control because they can elicit muscle responses in participants not maintaining standing balance (101-103). Consequently, it is not clear what (if any) principles specific to the control of quiet standing can be gained from mechanical vibrations targeting muscle(s) or cutaneous receptors.

\section{Visual Perturbations}

Visual perturbations can induce illusions of self-motion (i.e., vection) because retinal signals encode motion of the body and/or the environment. The brain must disambiguate these visual signals in order to control standing balance. For example, when standing on an idle train and viewing another train moving slowly, a perception that your train is moving may emerge. Researchers have exploited this ambiguity to investigate the role of visual cues on postural orientation and control of standing balance by imposing discrete translation or rotary visual perturbations (e.g., movements of the walls within a room or projected image). Standing participants exhibit welldefined compensatory balance responses (and illusions of selfmotion) to discrete visual perturbations (104-109). The wholebody responses occur in the same direction as the visual motion $(104,110,111)$. One explanation for this response is that the imposed visual stimuli are partially interpreted as a consequence of body motion. Hence, when the visual surround moves backwards (i.e., toward a subject), the balance system interprets the perturbation as self-motion in a forward direction which is corrected by leaning backwards. Consequently, visual perturbations provide a window into how visual signals of self-motion contribute to the control of standing balance. 

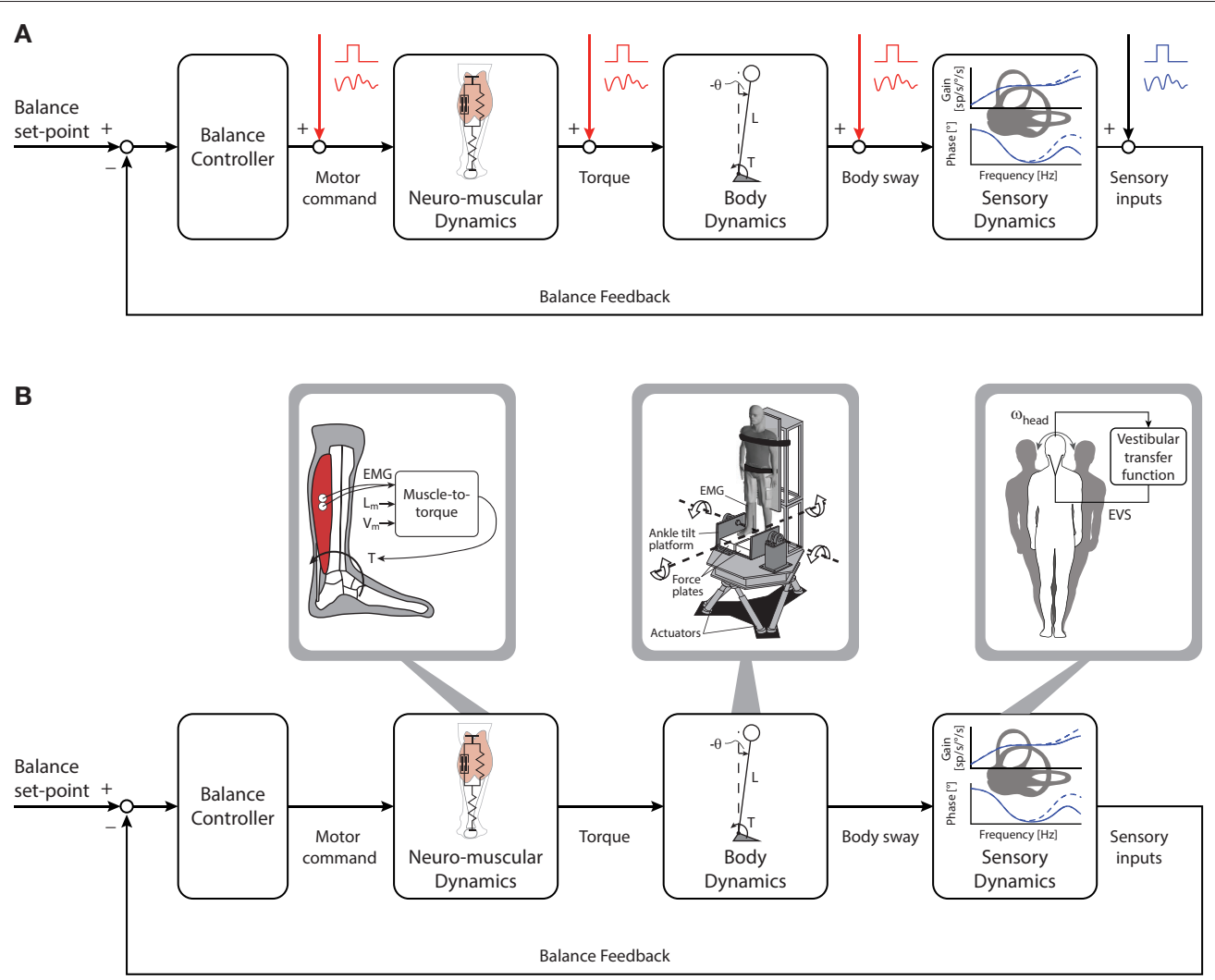

FIGURE 2 | Imposed perturbations and manipulations of the balance control loop. (A): Mechanical and/or sensory perturbations can be imposed at the various stages of the control loop to produce external error signals independent from the ongoing control of quiet standing. Imposed perturbations can be delivered as discrete (e.g., square wave signal) or continuous (oscillatory signal) disturbances to evoke compensatory postural responses. (B) Manipulations of the balance control loop aim to simulate and/or modify the relationship between sensory and motor cues of ongoing balance control (i.e. human in the loop manipulations). These manipulations can be used to mimic or alter the dynamics of different components of the balance system through the use of robotic systems and sensory stimulation techniques. Transfer functions characterizing muscle contraction (electromyography [EMG], muscle length [ $\left.\mathrm{Lm}_{\mathrm{m}}\right]$ and muscle velocity $\left[\mathrm{V}_{\mathrm{m}}\right]$ ) to torque output can be used to manipulate the ongoing effect of motor command (left). Similarly, a robotic balance simulator can be used to mimic and manipulate balance mechanics (middle). Torque delivered by the subject is used to control platform motion: this places the subject in-the-loop and allows for ongoing manipulation of standing balance. In addition, manipulations to sensor dynamics can be achieved, for example, by using instantaneous head velocity and transfer functions of the vestibular system to deliver an electrical vestibular stimulus that modulates the ongoing vestibular afferent firing rates (right). whead, head rotational velocity; EVS, electrical vestibular stimulation.

Visually-induced balance responses decrease as the amplitude of visual motion increases $(20,112-115)$. Dokka et al. (114) proposed that because slow visual signals of whole-body motion are more probable than faster motion, the slower visual signals are more likely to be interpreted as originating from self-motion. Day et al. (115) further reported a later visually-evoked balance response $(\sim 0.7 \mathrm{~s}$ latency) that increases with stimulus velocity. They suggested that the later visuallyevoked balance response is related to the alignment of the body to the erroneous estimate of gravity, an estimate that is biased by a prolonged stimulus of visual motion (107, $110,115)$. This concept is reminiscent of the multisensory integration processes required to estimate the orientation of gravity from the otolith signals that can lead to an erroneous interpretation of translation $(49,116-119)$. It further highlights the usefulness of visual perturbations to explore and reveal physiological principles underlying the control of standing balance.

\section{Vestibular Perturbations}

Natural activation of the vestibular system requires movements of the head-in-space. Imposed head movements to examine the role of vestibular inputs on standing balance, however, have a limited use because head motion typically results in concomitant activation of other sensory signals. An isolated vestibular perturbation can be achieved by delivering electrical vestibular stimuli (EVS) through electrodes applied over the mastoid processes (assuming subjects keep their eyes closed). Application of such electrical stimuli modulates the activity of all vestibular afferents (increasing firing rates of all afferents under the cathodal electrode and decreasing under the anodal electrode), without having to move the head in space (120124). Based on the anatomy and physiology of the vestibular system, bilateral binaural EVS is assumed to generate a vestibular error signal of head roll velocity around an axis pointing posterior and $\sim 18^{\circ}$ up from Reid's plane (125-128). Although EVS represents a non-physiological stimulus (i.e., activation of all 
vestibular afferents), responses elicited by EVS are only present in appendicular muscles when subjects are actively engaged in the task of balancing the whole-body (129-131). Hence, EVS can be used to investigate the vestibular control of balance and how vestibular signals are integrated, processed and relied upon for balance control [see reviews, $(24,125)]$. We note, however, that this task dependency is not a ubiquitous feature because EVS evokes vestibulocollic reflexes in neck muscles even when the head and body are fully supported (132).

In standing participants, EVS evokes an unexpected vestibular error signal that requires a compensatory balance response to maintain an upright posture $(125,129,133)$. The EVS-evoked error signal of head motion is head-referenced, such that its influence on standing balance depends on the orientation of the head with respect to the feet. Consequently, vestibularevoked muscle and whole-body balance responses are spatially transformed based on head orientation with respect to the feet (134-137). This indicates that the whole-body responses evoked by an isolated vestibular perturbation (EVS) involve multisensory integration of information related to head-onfeet posture (e.g., via proprioceptive inputs) with vestibular cues of motion. Furthermore, the direction of the vestibularevoked balance responses is influenced by body stability, whereby muscle and balance responses evoked by EVS are larger in the direction where postural stability is reduced $(138,139)$. This directional modulation of the vestibular-evoked balance responses based on balance stability without changes in sensory feedback may confound conclusions regarding sensory upweighting of vestibular signals associated with experimental changes in sensory information (e.g., sway referencing or closing the eyes). This is because altering sensory information while balancing may decrease postural stability (i.e., increase sway), making it difficult to attribute the modulation of vestibularevoked responses to changes in relative sensory information or changes in postural stability and upright position (140). Finally, the task-dependent characteristics of vestibular-evoked balance responses further suggest that they are not indicative of simple reflex arcs but instead reflect organized balance responses involving the integration of multiple sensory and motor cues $(139,141,142)$.

\section{SENSORIMOTOR MANIPULATIONS TARGETING THE ONGOING CONTROL OF STANDING BALANCE}

As discussed in section Imposed External Perturbations to Characterize Standing Balance, imposed perturbations enable the identification and modeling of fundamental principles underlying standing balance. But these approaches must be interpreted within the framework of disturbances external to ongoing control of quiet standing. An alternative approach involves continuous sensory and/or mechanical manipulations of the balance control loop aimed at simulating or modifying the ongoing control of quiet standing balance (see Figures 2B, 3 ). In other words, these manipulations are designed to modify feedback relationships within the balance control loop such that their effects are a function of the action of the subject (i.e. human in the loop manipulations). In addition, they must carefully match the dynamics of the sensory, motor and mechanical systems involved in standing balance, often requiring detailed knowledge of the neural code to be mimicked or elaborated by devices to induce these manipulations. Here, we review sensory and mechanical manipulations of the balance control loops that allow participants to experience controlled aspects of standing balance or altered sensorimotor conditions. Specifically, we discuss how replicating the sensors dynamics of standing balance can reveal how a specific cue is integrated and processed to maintain upright stability. In addition, we draw parallels between sensorimotor manipulations and specific clinical populations who can balance in the absence of specific sensory feedback cues (e.g., large-fiber sensor neuropathy or vestibular-loss). Where appropriate, we discuss limitations of sensorimotor manipulations and identify where additional work is needed.

\section{Somatosensory Cues}

The role of somatosensory cues in the control of standing balance can be partially investigated using ongoing mechanical manipulation of the support surface. Continuous manipulation of the support surface can be adjusted based on the participants' torque production and whole-body postural oscillations to minimize ankle plantar- and dorsi-flexor movements. This swayreferencing of the support surface reduces the contribution of lower limb receptors encoding ankle angle to the control of standing. The increase of whole-body oscillations observed under this condition has been interpreted as supporting the role of ankle somatoreceptors in the control of standing balance (144-147). Reports from the clinical literature add support to the importance of somatoreceptors in upright postural control: patients with large diameter afferent neuropathy (complete loss of proprioception) are unable to stand or walk without vision $(148,149)$. Sway-referencing the support surface to the postural oscillations, however, has mechanical consequences that must be taken into account when interpreting the standing balance behavior to this modified ankle somatosensory feedback. Because the ankle joint angle remains relatively constant as the body oscillates back and forth, minimal deformation of the ankle tissues (muscles, tendons, ligaments, skin) occurs. This prevents the development of length and velocity dependent passive forces that normally contribute to the stabilizing torque required to remain upright (17). Considering that passive forces are estimated to contribute between 10 and $90 \%$ of the net torque required to stand $(16,17,20,150)$, it is not clear what portion of the postural stability changes observed during sway-referencing are due to the contribution of ankle somatosensors versus the modulation of the active component of standing to compensate for a reduction in passive forces contributing to standing. A potential approach to explore these possibilities could involve simulating/altering the muscle activation to muscle torque transfer functions using robotic devices replicating the control of standing balance $(13,151,152)$ (see Figure 2B and Mechanical and Sensory Approaches). 
The isolated contribution of somatosensory cues to standing balance has been assessed using balance control of a bodyequivalent load (8). Participants supported by a rigid frame with their head immobile (minimizing visual and vestibular cues) balanced a load with their feet that mimics the dynamics of an inverted pendulum (8, 130, 146, 153-155) (see Figure 3B). To distinguish contributions from muscle proprioceptors and foot sole cutaneous cues, skin receptors have been minimized by cooling or anesthetizing the feet $(153,156)$. The general consensus from these experiments is that ankle muscle receptors provide adequate inputs for maintaining standing balance. Although the range and variability of the body-equivalent load oscillations were larger than for natural standing balance (where all cues are available), participants could stabilize the load with only cues from the ankle muscle proprioceptors (153). The similar frequency characteristics of "whole-body" sway between these conditions further supported the conclusion that ankle muscle receptors are sufficient to maintain standing balance. Confirmatory findings by other groups provide additional validation regarding this conclusion $(147,157)$.

Additional somatosensory information may be incorporated within the balance control loop through the use of light touch. When subjects make light contact with a stationary external reference-typically with a finger-postural sway is reduced despite the negligible mechanical stabilizing effect of touch (158, 159). This suggests that cues encoded from low contact forces are incorporated as a sensory signal contributing to the balance control loop. Improved standing balance stability has also been observed when two standing subjects make light finger contact with one another (160-162). Using a simple modeling approach, Reynolds and Osler (162) suggested that interpersonal contact while standing is beneficial even if the balance controller does not distinguish self and partner motion. Taken together, these studies highlight the potential for light touch to alter sensory feedback within the balance control loop.

\section{Visual Cues}

A simple method to manipulate visual cues is to have subjects stand with the eyes closed or in the dark. Compared to eyes open, eyes closed (or darkness) increases quiet whole-body oscillations $(9,38,163-165)$, but the low frequency components require long sampling durations of stance ( $>300$ s) to be captured accurately (14). The importance of visual information for standing has also been revealed by manipulating the number of fixation targets $(166,167)$, type of lighting (168) and depth cues (169171). In a series of experiments, Paulus et al. (38) reported increases in postural stability under conditions with improved visual acuity, increased area of the central visual field and increased retinal displacement (caused by decreasing the eyeobject distance). These observations emphasize that the influence of vision on standing balance is dependent on the features of the visual scene. An alternative approach is to keep visual signals constant on the retina (effectively sway-referencing vision) by having participants view a scene that moves according to the motion of the whole-body $(144,145,154,172)$. Under these conditions, balance was more unstable compared to when the eyes were closed $(145,173,174)$. McCollum et al.
(174) rationalized that this occurs because in the visual swayreferenced condition, there is a central integration conflict (or mismatch) between different sensory channels (i.e., visionvestibular, vision-somatosensory). Collectively, these studies suggest that visual cues contribute to standing balance, and are likely fused with other signals encoding whole-body with postural oscillations.

An alternative approach to determine the role of visual cues in standing balance involves determining if these cues alone are sufficient to remain upright (see Figure 3C). Nagata et al. (157) devised a computer-controlled inverted pendulum allowing participants to apply forces and moments to the ground but experiencing only the visual consequences of their motion. Participants were stable in space while a motor replicated the visual signals of balance according to their motor actionshence subjects attempted to balance an equivalent body load with sensory feedback limited mostly to visual cues (others included somatosensory cues of feet pressure changes and muscle contractions). Nagata et al. (157) reported that vision only contributed to the reduction of sway below $0.4 \mathrm{~Hz}$. This aligns with previous suggestions that vision may primarily contribute to the low frequency $(<1 \mathrm{~Hz})$ control of standing balance $(170,175,176)$. Although visual perturbations can evoke sway behavior as high as $\sim 2 \mathrm{~Hz}(20)$, responses tend to decline rapidly above $0.8 \mathrm{~Hz}$. Nagata et al. (157) argued that the processing of visual information was too slow such that vision provided only a minor influence on the control of standing balance. A limiting factor of their approach, however, was that the rotational axis of the visual enclosure was not collinear with the ankle joints (154). Loram and colleagues, in contrast, have shown that participants standing braced can balance a real or virtual inverted pendulum with similar mechanics of the standing body using their hand to move a spring or a joystick with only visual cues of motion $(155,177,178)$. To address this apparent discrepancy on the role of visual cues to maintain standing balance, we performed a simple experiment. Ten healthy subjects participated in this study after giving their written informed consent. The experiment protocol conformed to the Declaration of Helsinki and was approved by the University of British Columbia's Clinical Research Ethics Board. Similar to Fukuoka et al. (154), braced upright participants balanced with the expected visual cues of self-motion programmed to replicate the motion of an inverted pendulum in the anteroposterior direction (see Figure 3C). Initially, all participants $(n=10)$ exhibited difficulties in keeping the visual cues of motion within the balance limits (i.e., $6^{\circ}$ anterior and $3^{\circ}$ posterior). Sway variability was 5-6 times larger than when balancing a robotic simulator using all sensory cues (Figure 4A). After 5 days of training to balance with only visual cues of motion ( $\sim 20 \mathrm{~min}$ per day), their ability to balance within the programmed limits improved substantially (Figure 4B). Participants exhibited a $\sim 75 \%$ decrease in sway variability but this variability remained twice that observed when balancing with all sensory cues. These data show that although subjects exhibit initial difficulties in balancing with only visual cues of motion, they can adapt and use these cues to control standing balance with practice. 
A

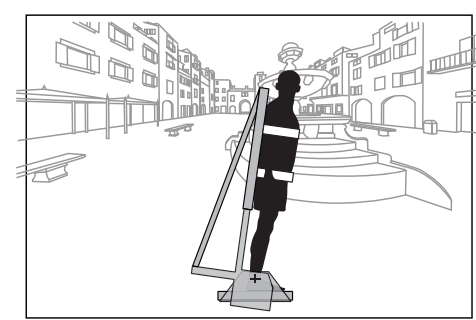

B
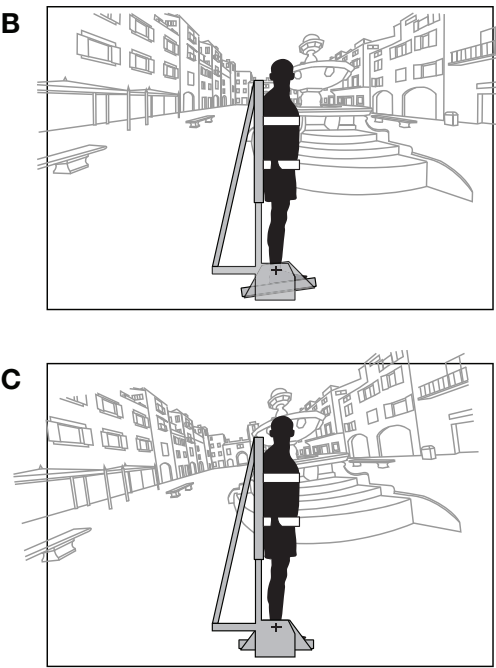

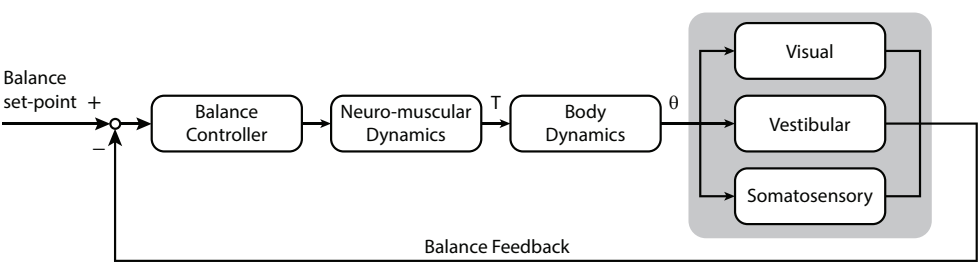

Balance Feedback
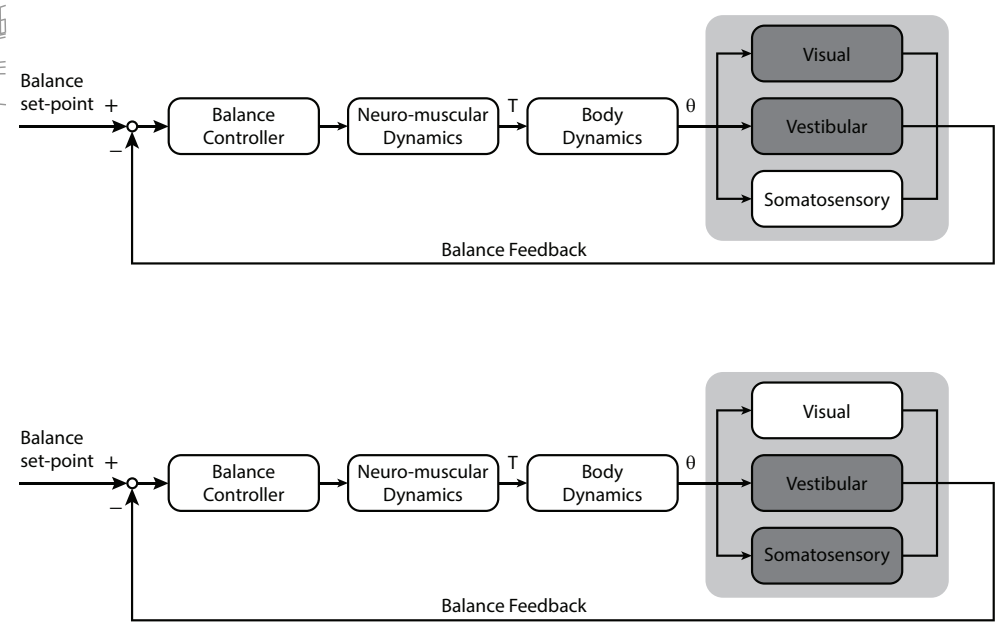

FIGURE 3 | Block diagrams of the varying sensory cue combinations that can be simulated using robotic balance platforms or mechanical devices. (A) Normal standing balance conditions where cues from visual, vestibular and somatosensory signals contribute to upright stance. Under these conditions, the foot is stationary, the whole-body moves and the head is moving relative to the visual scene. (B) A somatosensory-only balance condition. Subject's head and body are stationary in space in front of a stationary visual surround while the feet rotate, requiring subjects to balance a simulated inverted pendulum that mimics the body's mechanics with movement limited to their ankle joints. (C) A vision-only balance condition. Subjects are stationary in space while the visual scene is moving relative to the head, resulting in a balancing task that provides mostly balance-relevant visual cues. This condition was used here to re-examine the potential for standing subjects to use visual cues of motion (see Figure 4). Additional sensory cues (e.g. auditory) and other cue combinations could be considered. For example, by coupling simulated head motion with an electrical vestibular stimulus (see Figure 2B) it may be possible to provide dynamic vestibular cues of standing without actual motion. T, ankle torque; $\theta$, inverted pendulum angle. Portions of this figure were adapted from Shepherd (143).

\section{Vestibular Cues}

The contribution of vestibular cues has been inferred by assessing the standing balance behavior while carefully controlling the available cues to remain upright. One approach involved characterizing postural oscillations while sway-referencing vision as well as the support surface $(145,174)$. By minimizing visual and ankle somatosensory cues, Nashner and colleagues were targeting the role of vestibular signals in maintaining upright stability. Participants exhibited difficulty in maintaining upright posture when vision and ankle proprioception were sway referenced, sometimes experiencing falls $(145,174)$. However, the limitation discussed above regarding the lack of passive forces contributing to upright stability under the sway-referencing of the support surface also applies to these experiments. A second approach consisted of comparing postural oscillations during normal upright stance (including vestibular cues) and during balancing a body-equivalent load while braced (excluding vestibular cues). When limiting whole-body movements to the ankle joints in both conditions, Fitzpatrick et al. (153) showed that balance stability was similar if vestibular cues contributed to the control of balance or not, irrespective of visual cues. Altogether, observations from these two distinct approaches suggest that vestibular cues provide limited benefit over visual and somatosensory cues to the control of standing balance. In support of this idea, vestibular loss patients can maintain upright stance with vision and somatosensory cues (even at the onset of the deficit), and over time, the instability is reduced due to compensation processes (179-182) and possibly from neural adaptation such as that observed in non-human primates (183185).

Ongoing manipulation of vestibular cues according to postural oscillations was assessed in a different context by Héroux et al. (186). Participants were standing on foam with eyes closed while exposed to an electrical vestibular stimulus. The electrical stimulus was designed to replicate the general dynamics of primary semicircular afferents modulations during standing balance and coupled in real-time to the recorded movements of the head (see Figure 2B). Conceptually, this headcoupled vestibular stimulus increased or decreased vestibular gain depending on the polarity of the stimulus with respect to the 


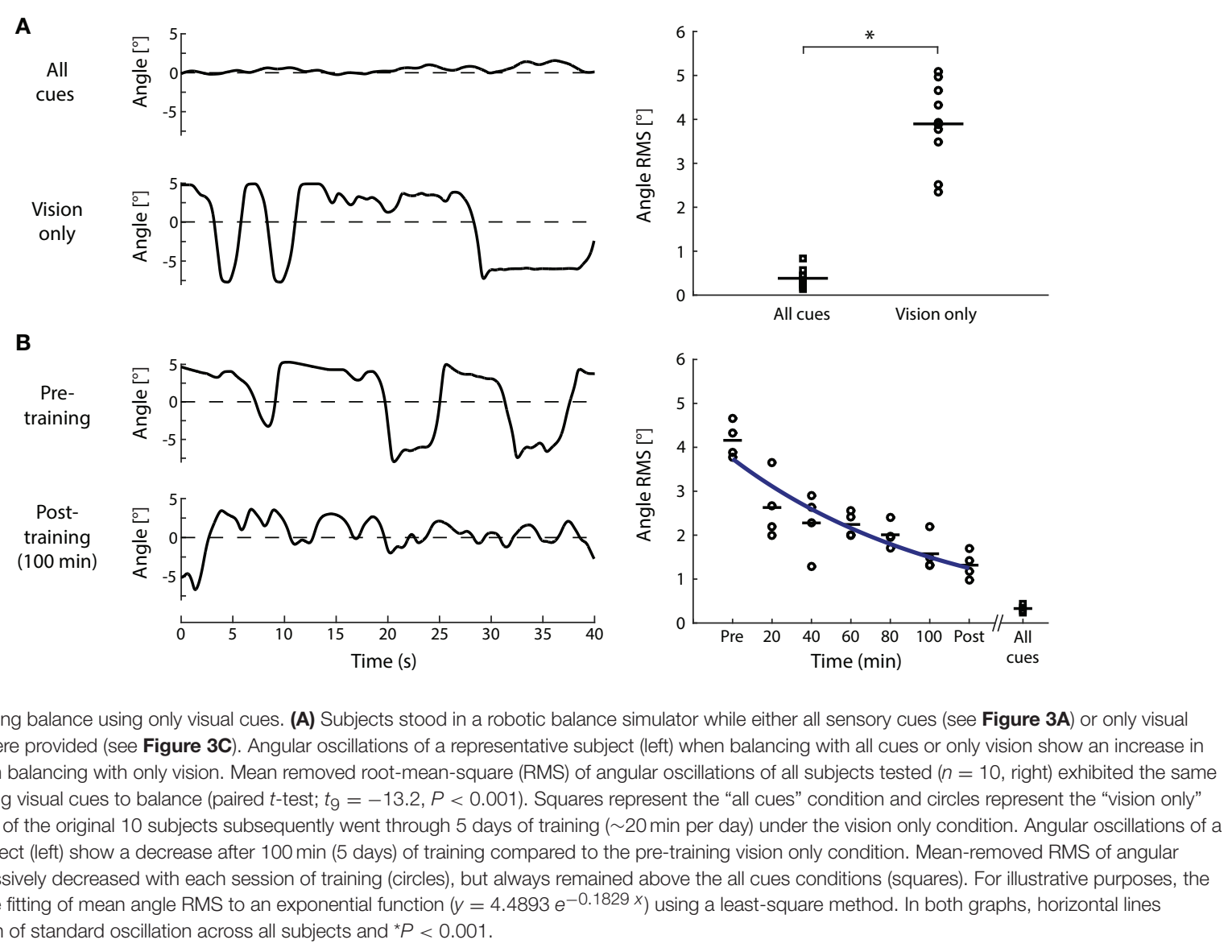

measured head motion. When the stimulus was applied, postural oscillations increased 4 -fold. This finding bears some similarity to the decreased postural stability observed in acute unilateral vestibular loss patients $(181,187,188)$ who are faced with asymmetric vestibular inputs. Although these results suggest that altering the gain of vestibular cues during standing influence the balance behavior, additional work is needed to determine if such vestibular cues of standing delivered in isolation (i.e., standing fixed to a rigid backboard) are sufficient to allow humans to balance upright.

\section{COMBINING MANIPULATIONS TARGETING THE ONGOING CONTROL OF QUIET STANDING BALANCE WITH IMPOSED EXTERNAL PERTURBATIONS}

Although manipulations targeting the ongoing control of standing balance can indicate limits of adaptability in the controller, there are limitations with interpreting standing behavior (forces, torques, sway) when sensory cues are manipulated in isolation. Specifically, while the combination of sensory cues can be well controlled, manipulations of the ongoing control of balance do not provide a known external perturbation signal. Van der Kooij et al. (57) compared different approaches to assess standing balance and showed that an external perturbation is needed to characterize the mechanisms governing balance. Applying imposed perturbations while controlling specific parameters of the ongoing control of standing combines the strengths of both approaches, affording a unique opportunity to reveal operating principles of the balance system and potentially revealing some of its inherent limitations. In the following section, we describe how imposed perturbations during well-controlled sensory manipulations have revealed fundamental features of standing balance such as intersensory interactions and re-calibration of sensory feedback loops. This includes the use of mechanical and robotic balance systems that allow for the replication of standing balance dynamics and provide users full control to virtualize parameters of the balance task. Finally, we briefly present an approach to alter the vestibular contribution to standing and discuss the resulting adaptation occurring in the control of standing balance.

\section{Mechanical and Sensory Approaches}

Pioneering work using a combination of perturbation approaches was conducted by Fitzpatrick et al. (130). The authors used their whole-body equivalent load device to explore how the vestibular control of standing balance-characterized with EVSevoked muscle responses-was modulated by the sensory cues contributing to postural stability. Fitzpatrick et al. (130) revealed 
strong context-dependency of the vestibular control of standing: vestibular-evoked muscle responses were absent when subjects balanced the body-equivalent load using only somatosensory cues. This suggests that although lower limb somatosensory cues are sufficient to maintain upright stance, balance-relevant vestibular feedback is required to engage the response to an external vestibular perturbation signal (130).

Cenciarini and Peterka (81) combined support surface perturbations (pseudorandom ankle tilt stimuli and swayreferenced conditions) with step EVS pulses to test predictions from their sensory re-weighting hypothesis (20). The authors showed that the amplitude of vestibular-evoked whole-body responses increased when concomitant perturbations were applied to the support surface and were largest when the ankle joint was sway-referenced. These observations corresponded well with predictions from their computational model and were interpreted as providing support for the sensory reweighting hypothesis $(79,80,189,190)$. In this case, the limited balance feedback from the ankle proprioceptors during sway-referencing was interpreted as requiring an increased contribution of vestibular signals for standing balance as reflected by the larger EVS-evoked responses. Note that, as similarly discussed in section Vestibular Perturbations, support surface perturbations and sensorimotor manipulations may influence balance stability which in turn modulates vestibular-evoked balance responses $(138,139)$. Carefully designed experiments are needed to determine the relative contribution of standing balance state (i.e., angular position and angular velocity) and sensory re-weighting on the modulation of vestibular-evoked balance responses.

To take advantage of the possibilities enabled by manipulations of the balance control loop, our group developed a robotic system that can replicate and/or modify specific parameters of the sensorimotor control of standing balance (Figure 2B) (151). Upright participants are braced to a rigid backboard mounted atop a six-degree of freedom Stewart mechanism. Through a computer simulation in which the mechanics, sensory feedback and environment of standing can be simulated or altered, the robot rotates the whole-body about the ankle joints based on the real-time ground reaction forces and moments applied by the participants. Motion of the robot can be restricted to the anterior-posterior direction and the force plates are mounted to an ankle-tilt platform, allowing independent control of whole-body and ankle movements (191). When programmed to simulate an inverted pendulum, movement of the subjects actuating the robot replicates the torque-angle relationship of the whole-body during unrestricted standing balance (13). Under these subject-in-the-balance-loop conditions, a plantar-flexor torque is necessary to maintain the body in a forward leaning position.

Using this robotic balance simulator, Luu et al. (131) revisited the hypothesis that balance-relevant vestibular feedback is required to engage the response to an external vestibular perturbation signal. First, Luu et al. (131) showed that vestibular feedback (whole-body sway) independent from the balance task was not sufficient to elicit muscle responses to vestibular stimuli. Forbes et al. (139) complemented these findings by allowing participants to balance only along one plane (anteroposterior or mediolateral) while controlling the orientation of the headand the direction of the vestibular-induced error signal. As the direction of balance and that of the vestibular error signal rotate orthogonally to one another, vestibular-evoked muscle responses are progressively suppressed even though subjects are engaged in balance. Hence, the vestibular contribution to balance muscle activity depends not only on the contribution of vestibular feedback to the ongoing muscle activity but also on the crossproduct of the direction of balance instability and the direction of the induced vestibular error. Second, Luu et al. (131) addressed the possibility that balance-relevant vestibular signals must be temporally and spatially coupled to the motor commands to engage the vestibular control of standing. Participants stood atop the robotic balance system under two conditions: (1) with coupled sensory and motor signals, where subjects actively controlled the motion of their body in space by modulating their ankle torques (replicating normal standing), and (2) with decoupled sensory and motor signals, where the robot imperceptibly took control and imposed whole-body motion to the subjects following a pre-determined trajectory independent of their ankle torques. For the latter condition, subjects continued to actively modulate their ankle torques despite them not influencing the motion of their body, thus resulting in a discrepancy between predicted and actual sensory feedback associated with the standing balance task. Despite subjects demonstrating poor conscious awareness of the transitions between these two conditions (i.e., self vs. robot-controlled whole-body motion), vestibular-evoked muscle responses were attenuated when motor and sensory cues of balance were decoupled. These observations suggest that congruency between predicted and actual sensory signals is required to engage the vestibular control of standing balance. One caveat to these observations, however, is that the congruency of multiple balance feedback cues (visual, vestibular, somatosensory) was manipulated simultaneously (i.e., either all congruent or none were congruent). Hence, it remains unclear how individual sensory cues interact with the balance responses to vestibular error signals.

Forbes et al. (139) further used the robotic balance system to explore the adaptability of the control of standing balance. They modified the balance simulation by reversing the direction of whole-body motion produced by the measured ankle torques, effectively inverting the roles of the muscles controlling balance in the anteroposterior plane. Subjects were instructed to close their eyes and the ankle-torque relationship was maintained, mainly targeting the reversal to vestibular feedback. Under these reversed conditions, a dorsi-flexor torque is necessary to maintain the body in a forward leaning position. Participants adapted within $30-90 \mathrm{~s}$ to the reversed balance control. When EVS was applied, subjects swayed in the same direction for both the control and reversed balance conditions. To induce the same whole-body movement, the motor outputs from the balance controller (e.g., torque and muscle responses), however, were reversed and delayed. This indicates that the neural centers controlling standing balance can rapidly integrate the state of the relationship between motor commands and whole-body sensory 
feedback, and generate appropriate muscle responses to correct for the induced vestibular error signals. Such swift re-associations of sensorimotor relationships may reflect our flexibility to maintain bipedal postures in varied settings, like when stepping from shore onto a stand-up paddle board. Similar reversals of vestibulomotor responses have been observed in the vestibuloocular reflex (VOR) during exposure to optical reversals of vision, although adaptation typically required days or weeks to fully invert vestibular-evoked eye movements (192-194). Despite the temporal differences in the balance and VOR adaptation to the reversals, the detailed characterization of the cellular mechanisms in the cerebellum and vestibular nuclei involved in the plasticity of the VOR [see review by Cullen and Mitchell (195)] may point toward similar neurophysiological processes playing a role in vestibulomotor adaptations for balance. In non-human primates, adaptations in neuronal recordings of vestibular nuclei and cerebellar neurons have been observed on a trial-by-trial basis (196). Over exposure to a novel relationship between motor commands and consequent head movement (altered headneck dynamics), neuronal responses adapt from encoding head motion as externally generated to one that is self-generated. The multisensory convergence of sensory afferents at the vestibular nuclei and their projections to descending spinal tracts $(197,198)$ suggest that the vestibular nuclei contribute to the adaptive mechanisms observed in the vestibular control of balance.

\section{Sensory and Sensory Approaches}

Carefully manipulating the information from multiple sensory inputs further allows one to explore inter-sensory interactions in standing balance. Several groups have investigated how varying the availability and quality of visual cues interacts with the vestibular-evoked balance response to EVS (129, 130, 171, 199, 200). Day and Guerraz (171) manipulated the quality of visual cues providing information regarding whole-body oscillations during standing balance. Participants stood in a dark room while viewing nothing, a single light-emitting diode, a two-dimensional array of light-emitting diodes or a threedimensional array of light-emitting diodes. The authors probed the vestibular control of balance using EVS under these different conditions to determine how the structure of visual cues related to standing balance influenced vestibular-evoked responses. In healthy controls, they showed that the early parts of vestibularevoked responses vary when pre-stimulus visual information differs (i.e., light or dark), even when the post-stimulus feedback visual environments are equivalent. Feedback effects from the post-stimulus environment were also observed, affecting the later parts of the balance response ( $>\sim 400 \mathrm{~ms}$ ). This setting of the vestibular channel's gain can explain how vestibular responses evoked in healthy controls change with the amount of available visual cues.

Mian and Day (138) explored how sensory information derived from light touch can influence the direction of the vestibular-evoked balance response. Standing subjects were probed with EVS while lightly touching a stationary flat surface aligned laterally to the subjects. Despite light touch providing negligible mechanical stabilizing effects on the body, the response to EVS was biased toward the anteroposterior direction. As sensory cues from light touch are thought to be transformed into ongoing proprioceptive feedback for standing balance, this suggests that the gain of the vestibular-evoked balance response is spatially-modulated by the orientation (or direction) of balancerelevant proprioceptive feedback. Careful interpretation of these findings is warranted because light touch also reduced wholebody sway in the mediolateral plane.

As stated above, Héroux et al. (186) designed biologicallyplausible head-coupled electrical vestibular stimuli to manipulate vestibular gain in healthy volunteers standing upright on foam with eyes closed. While balance oscillations increased four-fold when the electrical stimuli were applied (some subjects needed support to avoid a fall), the amplitude of the vestibular-evoked muscle responses (probed with an independent low-amplitude EVS signal) decreased. The authors further evaluated whether the participants could adapt to ongoing modulation of the vestibular cues associated with standing balance. The critical concept here was to determine if an imposed vestibular error signal that is coupled to the ongoing control of quiet standing balance can be calibrated and incorporated in the balance control loop. Participants were exposed to a re-calibration period of $240 \mathrm{~s}$ where the in-the-loop modified vestibular cues were provided with no foam and/or eyes open. Following this period, participants could maintain standing balance (on foam with eyes closed): postural sway and vestibulomotor response amplitudes returned to baseline. These results could not be explained by a down-regulation (or reweighting) of vestibular cues because matching levels of EVS that were uncoupled from head motion (hence remained an external imposed perturbation) did not yield any adaptation following a 240 s re-calibration period. Instead, these observations indicate that the balance controller can integrate an external vestibular error signal into its control loop and likely interpret it as a self-generated signal as long as that signal follows the expected sensory dynamics encoding ongoing quiet standing balance. Consequently, a vestibular signal that was deemed an error signal before re-calibration was transformed into a meaningful signal that was used to maintain upright balance.

\section{FUTURE DIRECTIONS}

Sensorimotor manipulations of the balance control loop can target how muscle activation is related to the ground reaction forces and moments acting on the subject as well as the sensory feedback experienced (perceived or not) by participants maintaining standing balance. Critical questions to address include determining the influence of the state of standing balance stability [see $(138,139)]$ on imposed perturbations, how sensory signals are used to control standing balance under challenging conditions along with the limits of our capability to maintain upright stance. As a specific example, Luu et al. (131) proposed that a spatial and temporal relationship between sensory and motor signals is required to engage the vestibular control of standing balance. The factors underlying this spatio-temporal relationship need to be explored as well as their influence on our capability to remain upright. Future experiments should 
also target how imposed visual perturbations are integrated in the control of standing balance under manipulations similar to those explored using imposed electrical vestibular stimuli (131, $138,139)$ to determine if previous findings can be generalized and truly reflect fundamental mechanisms of the balance control loop. Building on the work from Héroux et al. (186), it is also conceivable to imagine innovative ways to characterize the unique contribution of sensory cues to the control of standing balance. As we learn more about the dynamics of standing and the resulting code from specific sensory afferents, artificial stimuli can be envisioned to replicate the neural code and assess its contribution to standing. For example, knowledge regarding the firing behavior of muscle spindle afferents during upright stance would permit the creation of a range of stimuli (intraneural electrical, mechanical or miniaturized robotics) to mimic it. The keys to such endeavors include a better understanding of the physiological code underlying standing balance and concerted efforts to replicate it during well-controlled balance-relevant experiments.

\section{CONCLUSIONS}

We have reviewed externally imposed perturbations and manipulations of the balance control loop that can be used to reveal the multisensory cue integration, task-dependent sensory processing and sensorimotor adaptation underlying the control of standing balance. We presented imposed external perturbations that elicit postural responses when the stimulus is related to the context of standing balance. These balance-specific approaches can provide important insight on the factors influencing the control of standing

\section{REFERENCES}

1. Assaiante C, Amblard B. An ontogenetic model for the sensorimotor organization of balance control in humans. Hum Movement Sci. (1995) 14:13-43. doi: 10.1016/0167-9457(94)00048-J

2. Pozzo T, Levik Y, Berthoz A. Head and trunk movements in the frontal plane during complex dynamic equilibrium tasks in humans. Exp Brain Res. (1995) 106:327-38. doi: 10.1007/BF00241128

3. Gage WH, Winter DA, Frank JS, Adkin AL. Kinematic and kinetic validity of the inverted pendulum model in quiet standing. Gait Post. (2004) 19:124-32. doi: 10.1016/S0966-6362(03)00037-7

4. Pinter IJ, van Swigchem R, van Soest AJK, Rozendaal LA. The dynamics of postural sway cannot be captured using a one-segment inverted pendulum model: a PCA on segment rotations during unperturbed stance. J Neurophysiol. (2008) 100:3197-208. doi: 10.1152/jn.01312.2007

5. Smith JW. The forces operating at the human ankle joint during standing. $J$ Anat. (1957) 91:545-64.

6. Gurfinkel VS, Osovets SM. Equilibrium dynamics of human vertical posture. Biofizika (1972) 17:478-86.

7. Nashner LM. Adapting reflexes controlling the human posture. Exp Brain Res. (1976) 26:59-72. doi: 10.1007/BF00235249

8. Fitzpatrick RC, Taylor JL, McCloskey DI. Ankle stiffness of standing humans in response to imperceptible perturbation: reflex and task-dependent components. J Physiol. (1992) 454:533-47. doi: 10.1113/jphysiol.1992.sp019278

9. Day BL, Steiger MJ, Thompson PD, Marsden CD. Effect of vision and stance width on human body motion when standing: implications balance. We also described manipulations of the balance control loop which allow for the modification of mechanical and/or sensory dynamics to target the ongoing control of standing balance. Finally, we presented how combining imposed perturbations and manipulations of the balance control loop, including robotics and sensory manipulations, can reveal important principles underlying the maintenance of standing balance such as spatio-temporal congruency between sensory and motor signals, rapid re-association of sensorimotor relationships and re-calibration of vestibular signals in the balance control loop. We reason that by carefully considering the neural code of quiet standing, wellcontrolled experiments can utilize these combined imposed perturbations and manipulations of the balance control loop approaches to uncover the fundamental mechanisms of balance control.

\section{AUTHOR CONTRIBUTIONS}

$\mathrm{BR}, \mathrm{PAF}$, and J-SB contributed to conception and design of the review. RT collected and analyzed the data. BR and J-SB wrote the first draft of the manuscript. All authors contributed to manuscript revisions, and read and approved the submitted version.

\section{FUNDING}

The research leading to these results is supported by (1) the Netherlands Organization for Scientific Research (NWO \#016.Veni.188.049, PAF), and (2) the Natural Sciences and Engineering Research Council of Canada (J-SB). for afferent control of lateral sway. J Physiol. (1993) 469:479-99. doi: 10.1113/jphysiol.1993.sp019824

10. Winter DA. Human balance and posture control during standing and walking. Gait Post. (1995) 3:193-214. doi: 10.1016/0966-6362(96) 82849-9

11. Winter DA, Patla AE, Prince F, Ishac M, Gielo-Perczak K. Stiffness control of balance in quiet standing. J Neurophysiol. (1998) 80:1211-21. doi: 10.1152/jn.1998.80.3.1211

12. Rougier P, Farenc I. Adaptative effects of loss of vision on upright undisturbed stance. Brain Res. (2000) 871:165-74. doi: 10.1016/S0006-8993(00)02357-X

13. Luu BL, Huryn TP, Van der Loos HF, Croft EA, Blouin J-S. Validation of a robotic balance system for investigations in the control of human standing balance. IEEE Trans Neural Syst Rehabil Eng. (2011) 19:382-90. doi: 10.1109/TNSRE.2011.2140332

14. van der Kooij H, Campbell AH, Carpenter MG. Sampling duration effects on center of pressure descriptive measures. Gait Post. (2011) 34:19-24. doi: 10.1016/j.gaitpost.2011.02.025

15. Winter DA, Patla AE, Rietdyk S, Ishac MG. Ankle muscle stiffness in the control of balance during quiet standing. J Neurophysiol. (2001) 85:2630-3. doi: 10.1152/jn.2001.85.6.2630

16. Morasso PG, Sanguineti V. Ankle muscle stiffness alone cannot stabilize balance during quiet standing. J Neurophysiol. (2002) 88:2157-62. doi: 10.1152/jn.2002.88.4.2157

17. Loram ID, Lakie M. Direct measurement of human ankle stiffness during quiet standing: the intrinsic mechanical stiffness is insufficient for stability. $J$ Physiol. (2002) 545:1041-53. doi: 10.1113/jphysiol.2002.025049 
18. Morasso PG, Schieppati M. Can muscle stiffness alone stabilize upright standing? J Neurophysiol. (1999) 82:1622-6. doi: 10.1152/jn.1999.82.3.1622

19. Loram ID, Kelly S, Lakie M. Human balancing of an inverted pendulum: is sway size controlled by ankle impedance? J Physiol. (2001) 532:879-91. doi: 10.1111/j.1469-7793.2001.0879e.x

20. Peterka RJ. Sensorimotor integration in human postural control. $J$ Neurophysiol. (2002) 88:1097-118. doi: 10.1152/jn.2002.88.3.1097

21. Kuo AD. An optimal state estimation model of sensory integration in human postural balance. J Neural Eng. (2005) 2:235-49. doi: 10.1088/1741-2560/2/3/S07

22. Loram ID, Maganaris CN, Lakie M. Active, non-spring-like muscle movements in human postural sway: how might paradoxical changes in muscle length be produced? J Physiol. (2005) 564:281-93. doi: 10.1113/jphysiol.2004.073437

23. Loram ID, Maganaris CN, Lakie M. Human postural sway results from frequent, ballistic bias impulses by soleus and gastrocnemius. J Physiol. (2005) 564:295-311. doi: 10.1113/jphysiol.2004.076307

24. Forbes PA, Chen A, Blouin J-S. Sensorimotor control of standing balance. In: Gait B, Day BL, Lord SR, editors. Handbook of Clinical Neurology. Vol. 159 (in press).

25. Franklin GF, Powell JD, Emami-Naeini A. Feedback Control of Dynamic Systems. Upper Saddle River, NJ: Prentice Hall (2009).

26. Forbes PA, Dakin CJ, Vardy AN, Happee R, Siegmund GP, Schouten $\mathrm{AC}$, et al. Frequency response of vestibular reflexes in neck, back, and lower limb muscles. J Neurophysiol. (2013) 110:1869-81. doi: 10.1152/jn. 00196.2013

27. Forbes PA, Siegmund GP, Schouten AC, Blouin J-S. Task, muscle and frequency dependent vestibular control of posture. Front Integr Neurosci. (2015) 8:94. doi: 10.3389/fnint.2014.00094

28. Goodwin GM, McCloskey DI, Matthews PB. The contribution of muscle afferents to kinaesthesia shown by vibration induced illusions of movement and by the effects of paralysing joint afferents. Brain (1972) 95:705-48. doi: 10.1093/brain/95.4.705

29. Roll JP, Vedel JP. Kinaesthetic role of muscle afferents in man, studied by tendon vibration and microneurography. Exp Brain Res. (1982) 47:177-90. doi: 10.1007/BF00239377

30. Clark FJ, Burgess RC, Chapin JW, Lipscomb WT. Role of intramuscular receptors in the awareness of limb position. J Neurophysiol. (1985) 54:152940. doi: 10.1152/jn.1985.54.6.1529

31. Edin BB. Quantitative analysis of static strain sensitivity in human mechanoreceptors from hairy skin. J Neurophysiol. (1992) 67:1105-13. doi: 10.1152/jn.1992.67.5.1105

32. Edin BB. Quantitative analyses of dynamic strain sensitivity in human skin mechanoreceptors. J Neurophysiol. (2004) 92:3233-43. doi: $10.1152 /$ jn. 00628.2004

33. Collins DF, Refshauge KM, Todd G, Gandevia SC. Cutaneous receptors contribute to kinesthesia at the index finger, elbow, and knee. J Neurophysiol. (2005) 94:1699-706. doi: 10.1152/jn.00191.2005

34. Proske U, Gandevia SC. The proprioceptive senses: their roles in signaling body shape, body position and movement, and muscle force. Physiol Rev. (2012) 92:1651-97. doi: 10.1152/physrev. 00048.2011

35. Edin BB, Johansson N. Skin strain patterns provide kinaesthetic information to the human central nervous system. J Physiol. (1995) 487:243-51. doi: 10.1113/jphysiol.1995.sp020875

36. Kennedy PM, Inglis JT. Distribution and behavior of glabrous cutaneous receptors in the human foot sole. J Physiol. (2002) 538:995-1002. doi: 10.1113/jphysiol.2001.013087

37. Strzalkowski ND, Peters RM, Inglis JT, Bent LR. Cutaneous afferent innervation of the human foot sole: what can we learn from single unit recordings? J Neurophsyiol. (2018) 120:1233-46. doi: 10.1152/jn. 00848.2017

38. Paulus WM, Straube A, Brandt T. Visual stabilization of posture. Physiological stimulus characteristics and clinical aspects. Brain (1984) 107:1143-63. doi: 10.1093/brain/107.4.1143

39. Simpson JI. The accessory optic system. Ann Rev Neurosci. (1984) 7:13-41. doi: 10.1146/annurev.ne.07.030184.000305
40. Giolli RA, Blanks RH, Lui F. The accessory optic system: basic organization with an update on connectivity, neurochemistry, and function. Prog Brain Res. (2006) 151:407-40. doi: 10.1016/S0079-6123(05) 51013-6

41. Ghafouri M, McIlroy WE, Maki BE. Initiation of rapid reach-andgrasp balance reactions: is a pre-formed visuospatial map used in controlling the initial arm trajectory? Exp Brain Res. (2004) 155:532-6. doi: 10.1007/s00221-004-1855-8

42. Zettel JL, Holbeche A, McIlroy WE, Maki BE. Redirection of gaze and switching of attention during rapid stepping reactions evoked by unpredictable postural perturbation. Exp Brain Res. (2005) 165:392-401. doi: 10.1007/s00221-005-2310-1

43. Angelaki DE, Cullen KE. Vestibular system: the many facets of a multimodal sense. Annu Rev Neurosci. (2008) 31:125-50. doi: 10.1146/annurev.neuro.31.060407.125555

44. Goldberg JM. Afferent diversity and the organization of central vestibular pathways. Exp Brain Res. (2000) 130:277-97. doi: 10.1007/s002210050033

45. Fernández C, Goldberg JM. Physiology of peripheral neurons innervating otolith organs of the squirrel monkey. III. Response dynamics. J Neurophysiol. (1976) 39:996-1008. doi: 10.1152/jn.1976.39.5.996

46. Hess BJ, Angelaki DE. Inertial vestibular coding of motion: concepts and evidence. Curr Opin Neurobiol. (1997) 7:860-6. doi: 10.1016/S0959-4388(97)80147-X

47. Mergner T, Glasauer S. A simple model of vestibular canalotolith signal fusion. Ann N Y Acad Sci. (1999) 871:430-4. doi: 10.1111/j.1749-6632.1999.tb09211.x

48. Green AM, Angelaki DE. An integrative neural network for detecting inertial motion and head orientation. J Neurophysiol. (2004) 92:905-25. doi: 10.1152/jn.01234.2003

49. Laurens J, Angelaki DE. The functional significance of velocity storage and its dependence on gravity. Exp Brain Res. (2011) 210:407-22. doi: 10.1007/s00221-011-2568-4

50. Urbantschitsch V. Über Störungen des Gleichgewichtes und Scheinbewegungen [On disturbances of the equilibrium and illusory motions]. Zeitschrift Ohrenheilkunde (1897) 31:234-94.

51. Clark B, Graybiel A. The effect of angular acceleration on sound displacement: the audiogyral illusion. J Psychol. (1949) 28:235-44. doi: 10.1080/00223980.1949.9916005

52. Lackner JR. Induction of illusory self-rotation and nystagmus by a rotating sound field. Aviat Space Environ Med. (1977) 48:129-31.

53. Campos J, Ramkhalawansingh R, Pichora-Fuller MK. Hearing, selfmotion perception, mobility, and aging. Hear Res. (2018) 369:42-55. doi: 10.1016/j.heares.2018.03.025.

54. Peterka RJ. Postural control model interpretation of stabilogram diffusion analysis. Biol Cybern. (2000) 82:335-43. doi: 10.1007/s0042200 50587

55. Maurer C, Peterka RJ. A new interpretation of spontaneous sway measures based on a simple model of human postural control. J Neurophysiol. (2005) 93:189-200. doi: 10.1152/jn.00221.2004

56. Nielsen JB. Motoneuronal drive during human walking. Brain Res Rev. (2002) 40:192-201. doi: 10.1016/S0165-0173(02)00201-1

57. van der Kooij H, van Asseldonk E, van der Helm FCT. Comparison of different methods to identify and quantify balance control. J Neurosci Methods (2005) 145:175-203. doi: 10.1016/j.jneumeth.2005. 01.003

58. Ting LH. Dimensional reduction in sensorimotor systems: a framework for understanding muscle coordination of posture. Prog Brain Res. (2007) 165:299-321. doi: 10.1016/S0079-6123(06)65019-X

59. Mergner T. A neurological view on reactive human stance control. Annu Rev Control (2010) 34:177-98. doi: 10.1016/j.arcontrol.2010. 08.001

60. Diener HC, Bootz F, Dichgans J, Bruzek W. Variability of postural "reflexes" in humans. Exp Brain Res. (1983) 52:423-8.

61. Keshner EA, Allum JHJ, Pfaltz CR. Postural coactivation and adaptation in the sway stabilizing responses of normals and patients with bilateral vestibular deficit. Exp Brain Res. (1987) 69:77-92. doi: 10.1007/BF002 47031 
62. Keshner EA, Allum JH, Honegger F. Predictors of less stable postural responses to support surface rotations in healthy human elderly. J Vestib Res. (1993) 3:419-29.

63. Allum JHJ, Honegger F. Interactions between vestibular and proprioceptive inputs triggering and modulating human balance-correcting responses differ across muscles. Exp Brain Res. (1998) 121:478-94. doi: $10.1007 /$ s002210050484

64. Nashner LM. Fixed patterns of rapid postural responses among leg muscles during stance. Exp Brain Res. (1977) 30:13-24. doi: 10.1007/BF00237855

65. McIlroy WE, Maki BE. Changes in early 'automatic' postural responses associated with the prior-planning and execution of a compensatory step. Brain Res. (1993) 631:203-11.

66. Huang QM, Hodges PW, Thorstensson A. Postural control of the trunk in response to lateral support surface translations during trunk movement and loading. Exp Brain Res. (2001) 141:552-9. doi: 10.1007/s00221-0010896-5

67. Carpenter MG, Thorstensson A, Cresswell AG. Deceleration affects anticipatory and reactive components of triggered postural responses. Exp Brain Res. (2005) 167:433-45. doi: 10.1007/s00221-005-0049-3

68. Cresswell AG, Oddsson L, Thorstensson A. The influence of sudden perturbations on trunk muscle activity and intraabdominal pressure while standing. Exp Brain Res. (1994) 98:336-41. doi: 10.1007/BF002 28421

69. Aruin AS, Latash ML. The role of motor action in anticipatory postural adjustments studied with self-induced and externally triggered perturbations. Exp Brain Res. (1995) 106:291-300. doi: 10.1007/BF002 41125

70. Gilles M, Wing AM, Kirker SG. Lateral balance organisation in human stance in response to a random or predictable perturbation. Exp Brain Res. (1999) 124:137-44. doi: 10.1007/s002210050607

71. Nashner LM. A model describing vestibular detection of body sway motion. Acta Otolaryngol. (1971) 72:429-36. doi: 10.3109/000164871091 22504

72. Allum JHJ. Organization of stabilizing reflex responses in tibialis anterior muscles following ankle flexion perturbations of standing man. Brain Res. (1983) 264:297-301. doi: 10.1016/0006-8993(83)90828-4

73. Horak FB, Nashner LM. Central programming of postural movements: adaptation to altered support-surface configurations. J Neurophysiol. (1986) 55:1369-81. doi: 10.1152/jn.1986.55.6.1369

74. Carpenter MG, Allum JH, Honegger F. Directional sensitivity of stretch reflexes and balance corrections for normal subjects in the roll and pitch planes. Exp Brain Res. (1999) 129:93-113. doi: 10.1007/s0022100 50940

75. Allum JHJ, Carpenter MG, Adkin AL. Balance control analysis as a method for screening and identifying balance deficits. Ann N Y Acad Sci. (2001) 942:413-27. doi: 10.1111/j.1749-6632.2001.tb03763.x

76. Torres-Oviedo G, Macpherson JM, Ting LH. Muscle synergy organization is robust across a variety of postural perturbations. J Neurophysiol. (2006) 96:1530-46. doi: 10.1152/jn.00810.2005

77. Maki BE, Holliday PJ, Fernie GR. A posture control model and balance test for the prediction of relative postural stability. IEEE Trans Biomed Eng. (1987) 34:797-810. doi: 10.1109/TBME.1987.325922

78. Johansson R, Magnusson M, Akesson M. Identification of human postural dynamics. IEEE Trans Biomed Eng. (1988) 35:858-69. doi: 10.1109/10.7293

79. Maurer C, Mergner T, Peterka RJ. Multisensory control of human upright stance. Exp Brain Res. (2006) 171:231-50. doi: 10.1007/s00221-0050256-y

80. van der Kooij H, Jacobs R, Koopman B, van der Helm F. An adaptive model of sensory integration in a dynamic environment applied to human stance control. Biol Cybern. (2001) 84:103-15. doi: 10.1007/s004220000196

81. Cenciarini M, Peterka RJ. Stimulus-dependent changes in the vestibular contribution to human postural control. J Neurophysiol. (2006) 95:2733-50. doi: $10.1152 /$ jn.00856.2004

82. Goodworth AD, Peterka RJ. Identifying mechanisms of stance control: a single stimulus multiple output model-fit approach. J Neurosci Methods (2018) 296:44-56. doi: 10.1016/j.jneumeth.2017.12.015

83. Tresch MC, Saltiel P, Bizzi E. The construction of movement by the spinal cord. Nat Neurosci. (1999) 2:162-7. doi: 10.1038/5721
84. d'Avella A, Saltiel P, Bizzi E. Combinations of muscle synergies in the construction of a natural motor behavior. Nat. Neurosci. (2003) 6:300-8. doi: $10.1038 / \mathrm{nn} 1010$

85. Ting LH, Macpherson JM. A limited set of muscle synergies for force control during a postural task. J Neurophysiol. (2005) 93:609-13. doi: 10.1152/jn.00681.2004

86. Lockhart DB, Ting LH. Optimal sensorimotor transformations for balance. Nat Neurosci. (2007) 10:1329-36. doi: 10.1038/nn1986

87. Torres-Oviedo G, Ting LH. Muscle synergies characterizing human postural responses. J Neurophysiol. (2007) 98:2144-56. doi: 10.1152/jn. 01360.2006

88. Ting LH, Chiel HJ, Trumbower RD, Allen JL, McKay JL, Hackney ME, et al. Neuromechanical principles underlying movement modularity and their implications for rehabilitation. Neuron (2015) 86:38-54. doi: 10.1016/j.neuron.2015.02.042

89. Jeka JJ, Schoner G, Dijkstra T, Ribeiro P, Lackner JR. Coupling of fingertip somatosensory information to head and body sway. Exp Brain Res. (1997) 113:475-83. doi: 10.1007/PL00005600

90. Rogers MW, Wardman DL, Lord SR, Fitzpatrick RC. Passive tactile sensory input improves stability during standing. Exp Brain Res. (2001) 136:514-22. doi: $10.1007 /$ s002210000615

91. Wing AM, Johannsen L, Endo S. Light touch for balance: influence of a time-varying external driving signal. Phil Trans R Soc B (2011) 366:3133-41. doi: 10.1098/rstb.2011.0169

92. Asslander L, Smith CP, Reynolds RF. Sensory integration of a light touch reference in human standing balance. PLoS ONE (2018) 13:e197316. doi: 10.1371/journal.pone.0197316

93. Burke D, Hagbarth KE, Lofstedt L, Wallin BG. The responses of human muscle spindle endings to vibration of non-contracting muscles. J Physiol. (1976) 261:673-93. doi: 10.1113/jphysiol.1976.sp0 11580

94. Vedel JP, Roll JP. Response to pressure and vibration of slowly adapting cutaneous mechanoreceptors in the human foot. Neurosci Lett. (1982) 34:289-94. doi: 10.1016/0304-3940(82)90190-2

95. Ribot-Ciscar E, Vedel JP, Roll JP. Vibration sensitivity of slowly and rapidly adapting cutaneous mechanoreceptors in the human foot and leg. Neurosci Lett. (1989) 104:130-5. doi: 10.1016/0304-3940(89) 90342-X

96. Eklund G. General features of vibration-induced effects on balance. Ups J MedSci. (1972) 77:112-24. doi: 10.1517/03009734000000016

97. Kavounoudias A, Roll R, Roll JP. Specific whole-body shifts induced by frequency-modulated vibrations of human plantar soles. Neurosci Lett. (1999) 266:181-4. doi: 10.1016/S0304-3940(99)00302-X

98. Thompson C, Bélanger M, Fung J. Effects of bilateral achilles tendon vibration on postural orientation and balance during standing. Clin Neurophysiol. (2007) 118:2456-67. doi: 10.1016/j.clinph.2007. 08.013

99. Thompson C, Bélanger M, Fung J. Effects of plantar cutaneo-muscular and tendon vibration on posture and balance during quiet and perturbed stance. Hum Movement Sci. (2011) 30:153-71. doi: 10.1016/j.humov.2010. 04.002

100. Kavounoudias A, Roll R, Roll JP. Foot sole and ankle muscle inputs contribute jointly to human erect posture regulation. J Physiol. (2001) 532 (Pt 3):869-78. doi: 10.1111/j.1469-7793.2001.0869e.x

101. Eklund G, Hagbarth KE. Normal variability of tonic vibration reflexes in man. Exp Neurol. (1966) 16:80-92. doi: 10.1016/0014-4886(66)90088-4

102. Stam J, Tan KM. Tendon reflex variability and method of stimulation. Electroencephalogr Clin Neurophysiol. (1987) 67:463-7. doi: 10.1016/0013-4694(87)90010-1

103. Chung SG, Van Rey EM, Bai Z, Rogers MW, Roth EJ, Zhang L. Aging-related neuromuscular changes characterized by tendon reflex system properties. Arch Phys Med Rehabil. (2005) 86:318-27. doi: 10.1016/j.apmr.2004. 04.048

104. Lishman JR, Lee DN. The autonomy of visual kinaesthesis. Perception (1973) 2:287-94. doi: 10.1068/p020287

105. Brandt T, Dichgans J, Koenig E. Differential effects of central versus peripheral vision on egocentric and exocentric motion perception. Exp Brain Res. (1973) 16:476-91. doi: 10.1007/BF00234474 
106. Lee DN, Lishman JR. Visual proprioceptive control of stance. J Hum Move Stud. (1975) 1:87-95.

107. Dichgans J, Held R, Young LR, Brandt T. Moving visual scenes influence the apparent direction of gravity. Science (1972) 178:1217-9. doi: 10.1126/science.178.4066.1217

108. Held R, Dichgans J, Bauer J. Characteristics of moving visual scenes influencing spatial orientation. Vis Res. (1975) 15:357-65. doi: 10.1016/0042-6989(75)90083-8

109. Dichgans J, Brandt T. Visual-vestibular interaction: effects on self-motion perception and postural control. In: Held R, Leibowitz HW, Teuber HL, editors. Handbook of Sensory Physiology: Perception. Berlin, Heidelberg: Springer Berlin Heidelberg (1978). p. 755-804.

110. Lestienne F, Soechting JF, Berthoz A. Postural readjustment induced by linear motion of visual scenes. Exp Brain Res. (1977) 45:363-84. doi: 10.1007/BF00235717

111. Dijkstra TMH, Gielen CCAM, Melis BJM. Postural responses to stationary and moving scenes as a function of distance to the scene. Hum Movement Sci. (1992) 11:195-203. doi: 10.1016/0167-9457(92) 90060-O

112. Peterka RJ, Benolken MS. Role of somatosensory and vestibular cues in attenuating visually induced human postural sway. Exp Brain Res. (1995) 105:101-10. doi: 10.1007/BF00242186

113. Mergner T, Schweigart G, Maurer C, Blumle A. Human postural responses to motion of real and virtual visual environments under different support base conditions. Exp Brain Res. (2005) 167:535-56. doi: 10.1007/s00221-005-0065-3

114. Dokka K, Kenyon RV, Keshner EA, Kording KP. Self versus environment motion in postural control. PLoS Comput Biol. (2010) 6:e1000680. doi: 10.1371/journal.pcbi.1000680

115. Day BL, Muller T, Offord J, Di Giulio I. Dual processing of visual rotation for bipedal stance control. J Physiol. (2016) 594:5661-71. doi: 10.1113/JP271813

116. Hess BJ, Angelaki DE. Oculomotor control of primary eye position discriminates between translation and tilt. J Neurophysiol. (1999) 81:394-8. doi: $10.1152 /$ jn.1999.81.1.394

117. Merfeld DM, Zupan L, Peterka RJ. Humans use internal models to estimate gravity and linear acceleration. Nature (1999) 398:615-8. doi: 10.1038/ 19303

118. Angelaki DE, Shaikh AG, Green AM, Dickman JD. Neurons compute internal models of the physical laws of motion. Nature (2004) 430:560-4. doi: 10.1038/nature02754

119. Dakin CJ, Rosenberg AS. Models and mechanisms of gravity estimation and verticality perception. In: Gait B, Day BL, Lord SR, editors. Handbook of Clinical Neurology. Vol. 159 (2018).

120. Goldberg JM, Fernández C, Smith CE. Responses of vestibular-nerve afferents in the squirrel monkey to externally applied galvanic currents. Brain Res. (1982) 252:156-60. doi: 10.1016/0006-8993(82)90990-8

121. Goldberg JM, Smith CE, Fernandez C. Relation between discharge regularity and responses to externally applied galvanic currents in vestibular nerve afferents of the squirrel monkey. J Neurophysiol. (1984) 51:1236-56. doi: $10.1152 /$ jn.1984.51.6.1236

122. Kim J, Curthoys IS. Responses of primary vestibular neurons to galvanic vestibular stimulation (GVS) in the anaesthetised guinea pig. Brain Res Bull. (2004) 64:265-71. doi: 10.1016/j.brainresbull.2004. 07.008

123. Kim K, Minor LB, Della Santina CC, Lasker DM. Variation in response dynamics for regular and irregular vestibular-nerve afferents during sinusoidal head rotations and currents in the chinchilla. Exp Brain Res. (2011) 210:643-9. doi: 10.1007/s00221-0112600-8

124. Kwan A, Mitchell DE, Forbes PA, Blouin JS, Cullen KE. Neural correlates of transmastoid galvanic vestibular stimulation in alert primates: linking vestibular afferent activation to perceptual, ocular and postural responses. Program No. 802.06. 2016 Neuroscience Meeting Planner. San Diego, CA: Society for Neuroscience (2016).

125. Fitzpatrick RC, Day BL. Probing the human vestibular system with galvanic stimulation. J Appl Physiol. (2004) 96:2301-16. doi: 10.1152/japplphysiol.00008.2004
126. Mian OS, Dakin CJ, Blouin JS, Fitzpatrick RC, Day BL. Lack of otolith involvement in balance responses evoked by mastoid electrical stimulation. $J$ Physiol. (2010) 588:4441-51. doi: 10.1113/jphysiol.2010.195222

127. Day BL, Marsden JF, Ramsay E, Mian OS, Fitzpatrick RC. Non-linear vector summation of left and right vestibular signals for human balance. J Physiol. (2010) 588:671-82. doi: 10.1113/jphysiol.2009.181768

128. Peters RM, Rasman BG, Inglis JT, Blouin J-S. Gain and phase of perceived virtual rotation evoked by electrical vestibular stimuli. J Neurophysiol. (2015) 114:264-73. doi: 10.1152/jn.00114.2015

129. Britton TC, Day BL, Brown P, Rothwell JC, Thompson PD, Marsden CD. Postural electromyographic responses in the arm and leg following galvanic vestibular stimulation in man. Exp Brain Res. (1993) 94:143-51. doi: 10.1007/BF00230477

130. Fitzpatrick R, Burke D, Gandevia SC. Task-dependent reflex responses and movement illusions evoked by galvanic vestibular stimulation in standing humans. J Physiol. (1994) 478:363-72. doi: 10.1113/jphysiol.1994.sp020257

131. Luu BL, Inglis JT, Huryn TP, Van der Loos HF, Croft EA, Blouin $\mathrm{J}$-S. Human standing is modified by an unconscious integration of congruent sensory and motor signals. J Physiol. (2012) 590:5783-94. doi: 10.1113/jphysiol.2012.230334

132. Forbes PA, Seigmund GP, Happee R, Schouten AC, Blouin J.-S. Vestibulocollic reflexes in the absence of head postural control. $J$ Neurophysiol. (2014) 112:1692-702. doi: 10.1152/jn.00343.2014

133. Day BL, Cauquil AS, Bartolomei L, Pastor MA, Lyon IN. Human body-segment tilts induced by galvanic stimulation: a vestibularly driven balance protection mechanism. J Physiol. (1997) 500:661-72. doi: 10.1113/jphysiol.1997.sp022051

134. Nashner LM, Wolfson P. Influence of head position and proprioceptive cues on short latency postural reflexes evoked by galvanic stimulation of the human labyrinth. Brain Res. (1974) 67:255-68. doi: 10.1016/0006-8993(74)90276-5

135. Lund S, Broberg C. Effects of different head positions on postural sway in man induced by a reproducible vestibular error signal. Acta Physiol Scand. (1983) 117:307-9. doi: 10.1111/j.1748-1716.1983.tb07212.x

136. Dakin CJ, Son GML, Inglis JT, Blouin J-S. Frequency response of human vestibular reflexes characterized by stochastic stimuli. J Physiol. (2007) 583:1117-27. doi: 10.1113/jphysiol.2007.133264

137. Reynolds RF. Vertical torque responses to vestibular stimulation in standing humans. J Physiol (Lond) (2011) 589:3943-53. doi: 10.1113/jphysiol.2011.209163

138. Mian OS, Day BL. Violation of the craniocentricity principle for vestibularly evoked balance responses under conditions of anisotropic stability. $J$ Neurosci. (2014) 34:7696-703. doi: 10.1523/JNEUROSCI.0733-14.2014

139. Forbes PA, Luu BL, Van der Loos HF, Croft EA, Inglis JT, Blouin J-S. Transformation of vestibular signals for the control of standing in humans. $J$ Neurosci. (2016) 36:11510-20. doi: 10.1523/JNEUROSCI.1902-16.2016

140. Son GM, Blouin J-S, Inglis JT. Short-duration galvanic vestibular stimulation evokes prolonged balance responses. J Appl Physiol. (2008) 105:1210-7. doi: 10.1152/japplphysiol.01398.2006

141. Dakin CJ, Héroux ME, Luu BL, Blouin J-S. Vestibular contribution to balance control in the medial gastrocnemius and soleus. J Neurophysiol. (2016) 115:1289-97. doi: 10.1152/jn.00512.2015

142. Dalton BH, Rasman BG, Inglis JT, Blouin J-S. The internal representation of head orientation differs for conscious perception and balance control. $J$ Physiol. (2017) 595:2731-49. doi: 10.1113/JP272998

143. Shepherd M. Intersensory Vestibular Control of Standing Balance. Master's thesis, Vancouver: University of British Columbia (2014).

144. Nashner LM, Black FO, Wall C. Adaptation to altered support and visual conditions during stance: patients with vestibular deficits. J Neurosci. (1982) 2:536-44. doi: 10.1523/JNEUROSCI.02-05-00536.1982

145. Black FO, Nashner LM. Vestibulospinal control differs in patients with reduced versus distorted vestibular function. Acta Otolaryngol. (1984) 406:110-4.

146. Ishida A, Imai S, Fukuoka Y. Analysis of the posture control system under fixed and sway-referenced support conditions. IEEE Trans Biomed Eng. (1997) 44:331-6. doi: 10.1109/10.568908 
147. Fukuoka Y, Nagata T, Ishida A, Minamitani H. Characteristics of somatosensory feedback in postural control during standing. IEEE Trans Neural Syst Rehabil Eng. (2001) 9:145-53. doi: 10.1109/7333.928574

148. Cole J. Pride and a Daily Marathon. Boston: MIT Press (1995).

149. Cole J. Large-fiber sensor neuropathy. In: Binder MD, Hirokawa N, Windhorst U, editors. Encyclopedia of Neuroscience, Berlin: Spinger (2009). p. 2102-7.

150. Casadio M, Morasso PG, Sanguineti V. Direct measurement of ankle stiffness during quiet standing: implications for control modelling and clinical application. Gait Post. (2005) 21:410-24. doi: 10.1016/j.gaitpost.2004.05.005

151. Huryn TP, Luu BL, Van der Loos HFM. (2010). Investigating human balance using a robotic motion platform. IEEE International Conference on Robotics and Automation. Anchorage, AK: IEEE. p. 5090-5.

152. Huryn TP, Blouin J-S, Croft EA, Koehle MS, Van der Loos HF. Experimental performance evaluation of human balance control models. IEEE Trans Neural Syst Rehabil Eng. (2014) 22:1115-27. doi: 10.1109/TNSRE.2014.2318351

153. Fitzpatrick R, Rogers DK, McCloskey DI. Stable human standing with lowerlimb muscle afferents providing the only sensory input. J Physiol. (1994) 480:395-403. doi: 10.1113/jphysiol.1994.sp020369

154. Fukuoka Y, Tanaka K, Ishida A, Minamitani H. Characteristics visual feedback in postural control during standing. IEEE Trans. Rehab. Eng. (1999) 7:427-34. doi: 10.1109/86.808946

155. Lakie M, Loram ID. Manually controlled human balancing using visual, vestibular and proprioceptive senses involves a common, low frequency neural process. J Physiol. (2006) 577:403-16. doi: 10.1113/jphysiol.2006.116772

156. Magnusson M, Enbom H, Johansson R, Pyykoo I. Significance of pressor input from the human feet in anterior-posterior postural control. Acta Otolaryngol. (1990) 110:182-8. doi: 10.3109/000164890091 22535

157. Nagata T, Fukuoka Y, Ishida A, Minamitani H. Analysis of role of vision in human upright posture control. Eng Med Biol Soc Proc. (2001) 2:1155-8. doi: 10.1109/IEMBS.2001.1020396

158. Holden M, Ventura J, Lackner JR. Stabilization of posture by precision contact of the index finger. J Vestib Res. (1994) 4:285-301.

159. Jeka JJ, Lackner JR. Fingertip contact influences human postural control. Exp Brain Res. (1994) 100:495-502. doi: 10.1007/BF02738408

160. Johannsen L, Guzman-Garcia A, Wing AM. Interpersonal light touch assists balance in the elderly. J Mot Behav. (2009) 41:397-9. doi: 10.3200/35-09-001

161. Johannsen L, Wing AM, Hatzitaki V. Contrasting effects of finger and shoulder interpersonal light touch on standing balance. J Neurophysiol. (2012) 107:216-25. doi: 10.1152/jn.00149.2011

162. Reynolds RF, Osler CJ. Mechanisms of interpersonal sway synchrony and stability. J R Soc Interface (2014) 11:20140751. doi: 10.1098/rsif.2014.0751

163. Travis RC. An experimental analysis of dynamic and static equilibrium. J Exp Psychol. (1945) 35:216-34. doi: 10.1037/h0059788

164. Edwards AS. Body sway and vision. J Exp Psychol. (1946) 36:526-35. doi: 10.1037/h0059909

165. Teasdale N, Stelmach GE, Breunig A. Postural sway characteristics of the elderly under normal and altered visual and support surface conditions. J Gerontol. (1991) 46:B238-B244. doi: 10.1093/geronj/ 46.6.B238

166. Bles W, Kapteyn TS, Brandt T, Arnold F. Mechanism of physiological height vertigo. II Posturography Acta Otolaryngol. (1980) 89:534-40. doi: $10.3109 / 00016488009127171$

167. Brandt T, Arnold F, Bles W, Kapteyn T. Mechanism of physiological height vertigo. I. Theoretical approach and psychophysics. Acta Otolaryngol. (1980) 89:512-23. doi: 10.3109/00016488009127169

168. Amblar B, Cremieux J, Marchand AR, Carblanc A. Lateral orientation and stabilization of human stance: static versus dynamic visual cues. Exp Brain Res. (1985) 61:21-37.

169. Guerraz M, Sakellari V, Burchill P, Bronstein AM. Influence of motion parallax in the control of spontaneous body sway. Exp Brain Res. (2000) 131:244-52. doi: 10.1007/s002219900307

170. Guerraz M, Gianna C, Burchill P, Gresty MA, Bronstein AM. Effect of visual surrounding motion on body sway in a $3 \mathrm{D}$ environment. Percept Psychophys. (2001) 63:47-58. doi: 10.3758/BF03200502
171. Day BL, Guerraz M. Feedforward versus feedback modulation of human vestibular-evoked balance responses by visual self-motion information. J Physiol. (2007) 582:153-61. doi: 10.1113/jphysiol.2007. 132092

172. Berthoz A, Soechting JF, Lacour M, Vidal PP. The role of vision in the control of posture during linear motion. Progress Brain Res. (1979) 50:197-209. doi: 10.1016/S0079-6123(08)60820-1

173. Nashner LM, McCollum G. The organization of human postural movements: a formal basis and experimental synthesis. Behav Brain Sci. (1985) 8:135-50. doi: $10.1017 / S 0140525 \mathrm{X} 00020008$

174. McCollum G, Shupert CL, Nashner LM. Organizing sensory information for postural control in altered sensory environments. J Theor Biol. (1996) 180:257-70. doi: 10.1006/jtbi.1996.0101

175. Vidal PP, Berthoz A, Millanvoye M. Difference between eye closure and visual stabilization in the control of posture in man. Aviat Space Environ Med. (1982) 53:166-70.

176. Bronstein AM, Buckwell D. Automatic control of postural sway by visual motion parallax. Exp Brain Res. (1997) 113:243-8. doi: 10.1007/BF024 50322

177. Loram ID, Lakie M, Gawthrop PJ. Visual control of stable and unstable loads: what is the feedback delay and extent of linear time-invariant control? J Physiol. (2009) 587:1343-65. doi: 10.1113/jphysiol.2008.166173

178. Loram ID, Gollee H, Lakie M, Gawthrop PJ. Human control of an inverted pendulum: is continuous control necessary? Is intermittent control effective? Is intermittent control physiological? J Physiol. (2011) 589:307-24. doi: 10.1113/jphysiol.2010.194712

179. Fetter M, Diener HC, Dichgans J. Recovery of postural control after an acute unilateral vestibular lesion in humans. J Vestib Res. (1991) 1:373-83.

180. Furman JM. Role of posturography in the management of vestibular patients. Otolaryngol Head Neck Surg. (1995) 112:8-15. doi: 10.1016/S0194-5998(95)70300-4

181. Peterka RJ, Statler KD, Wrisley DM, Horak FB. Postural compensation for unilateral vestibular loss. Front Neurol. (2011) 2:57. doi: 10.3389/fneur.2011.00057

182. Gauchard GC, Parietti-Winkler C, Lion A, Simon C, Perrin PP. Impact of pre-operative regular physical activity on balance control compensation after vestibular schwannoma surgery. Gait Post. (2013) 37:827. doi: 10.1016/j.gaitpost.2012.06.011

183. Sadeghi SG, Minor LB, Cullen KE. Neural correlates of motor learning in the vestibulo-ocular reflex: dynamic regulation of multimodal integration in the macaque vestibular system. J Neurosci. (2010) 30:10158-68. doi: 10.1523/JNEUROSCI.1368-10.2010

184. Sadeghi SG, Minor LB, Cullen KE. Multimodal integration after unilateral labyrinthine lesion: single vestibular nuclei neuron responses and implications for postural compensation. J Neurophysiol. (2011) 105:661-73. doi: $10.1152 /$ jn.00788.2010

185. Sadeghi SG, Minor LB, Cullen KE. Neural correlates of sensory substitution in vestibular pathways following complete vestibular loss. J Neurosci. (2012) 32:14685-95. doi: 10.1523/JNEUROSCI.249312.2012

186. Héroux ME, Law TC, Fitzpatrick RC, Blouin J-S. Cross-Modal Calibration of Vestibular Afference for Human Balance. PLoS ONE 10:e0124532. doi: 10.1371/journal.pone. 0124532

187. Mbongo F, Patko T, Vidal PP, Vibert N, Tran Ba Huy P, de Waele C. Postural control in patients with unilateral vestibular lesions is more impaired in the roll than in the pitch plane: a static and dynamic posturography study. Audiol Neurotol. (2005) 10:291-302. doi: 10.1159/0000 86081

188. Mbongo F, Quhen C, Vidal P, Tran Ba Huy P, de Waele C. Role of vestibular input in triggering and modulating postural responses in unilateral and bilateral vestibular loss patients. Audiol Neurotol. (2009) 14:130-8. doi: $10.1159 / 000162665$

189. Kiemel T, Oie KS, Jeka JJ. Multisensory fusion and the stochastic structure of postural sway. Biol Cybern. (2002) 87:262-77. doi: 10.1007/s00422-002-0333-2

190. Peterka RJ, Loughlin PJ. Dynamic regulation of sensorimotor integration in human postural control. J Neurophysiol. (2004) 91:410-23. doi: $10.1152 /$ jn. 00516.2003 
191. Pospisil ER, Luu BL, Blouin JS, Van der Loos HF, Croft EA. (2012). Independent ankle motion control improves robotic balance simulator. 2012 Annual International Conference of the IEEE Engineering in Medicine and Biology Society. San Diego, CA: IEEE. p. 6487-91.

192. Gonshor A, Jones GM. Extreme vestibulo-ocular adaptation induced by prolonged optical reversal of vision. J Physiol. (1976) 256:381-414. doi: 10.1113/jphysiol.1976.sp011330

193. Jones GM, Barlow HB, Gaze RM. Plasticity in the adult vestibulo-ocular refelx arc. Philos Trans R Roc Lond B Biol Sci. (1977) 278:319-34. doi: 10.1098/rstb.1977.0045

194. Berthoz A, Jones GM, Bégué AE. Differential visual-adaptation of vertical canal-dependent vestibulo-ocular reflexes. Exp Brain Res. (1981) 44:19-26.

195. Cullen KE, Mitchell DE. Procedural learning: VOR. In: Eichenbaum H, editor. Memory Sytems. Byrne JH, editor. Vol. 3 of Learning and Memory: A Comprehensive Reference, 2nd ed. Oxford: Academic Press (2017). p. 357-4.

196. Brooks JX, Carriot J, Cullen KE. Learning to expect the unexpected: rapid updating in primate cerebellum during voluntary self-motion. Nat Neurosci. (2015) 18:1310-7. doi: 10.1038/nn.4077

197. Abzug C, Maeda M, Peterson BW, Wilson VJ. Cervical branching of lumbar vestibulospinal axons. J. Physiol. (1974) 243:499-522. doi: 10.1113/jphysiol.1974.sp010764
198. Carleton SC, Carpenter MB. Afferent and efferent connections of the medial, inferior and lateral vestibular nuclei in the cat and monkey. Brain Res. (1983) 278:29-51. doi: 10.1016/0006-8993(83)90223-8

199. Smetanin BN, Popov KE, Shlykov VY. Changes in vestibular postural response determined by information content of visual feedback. Neurophysiology (1990) 22:66-72. doi: 10.1007/BF01052057

200. Asslander L, Peterka RJ. Sensory reweighting dynamics following removal and addition of visual and proprioceptive cues. J Neurophysiol (2016) 116 272-85. doi: 10.1152/jn.01145.2015

Conflict of Interest Statement: The authors declare that the research was conducted in the absence of any commercial or financial relationships that could be construed as a potential conflict of interest.

Copyright (c) 2018 Rasman, Forbes, Tisserand and Blouin. This is an open-access article distributed under the terms of the Creative Commons Attribution License (CC $B Y)$. The use, distribution or reproduction in other forums is permitted, provided the original author(s) and the copyright owner(s) are credited and that the original publication in this journal is cited, in accordance with accepted academic practice. No use, distribution or reproduction is permitted which does not comply with these terms. 